\title{
CAPACIDADE RELACIONAL E EXPERIÊNCIA EM ALIANÇAS ESTRATÉGICAS DE P\&D ENVOLVENDO A EMBRAPA E SEUS PARCEIROS EXTERNOS
}

\author{
REGIONAL CAPACITY AND EXPERIENCE IN STRATEGIC R\&D ALLIANCES INVOLVING EMBRAPA AND ITS \\ EXTERNAL PARTNERS
}

\section{LA CAPACIDAD RELACIONAL Y LA EXPERIENCIA EN ALIANZAS ESTRATÉGICAS DE P\&D INVOLUCRANDO LA EMBRAPA Y SUS SOCIOS EXTERNOS}

TAÍSA SCARIOT PREUSLER

Mestra

Empresa Brasileira de Pesquisa Agropecuária - Brasil taisa.s@hotmail.com ORCID: https://orcid.org/0000-0002-0136-9040

PRISCILA REZENDE DA COSTA Doutora

Universidade Nove de Junho - Brasil priscilarezende@yahoo.com.br ORCID: https://orcid.org/0000-0002-7012-0679

TATIANE BASEGGIO CRESPI Mestra

Empresa Brasileira de Pesquisa Agropecuária - Brasil

tatianebaseggiocrespi@gmail.com ORCID: https://orcid.org/0000-0001-9740-8069

GECIANE SILVEIRA PORTO Doutora

Universidade de São Paulo - Brasil geciane@usp.br ORCID: https://orcid.org/0000-0001-6104-3627

Submetido em: 19/02/2018 Aprovado em: 28/01/2019

Doi: alcance.v25n3(Set/Out).p291-314

\section{RESUMO}

Alianças estratégicas de P\&D são consideradas uma alternativa às instituições para gerar inovações. Dentre as capacidades que podem contribuir para o sucesso de uma aliança está a relacional (CR), isto é, um construto de gestão estratégica de alianças com lacunas de pesquisa ainda não verificadas empiricamente, tal como se a experiência com parceiros repetidos ou diversificados potencializa de forma distinta alianças que possuam ênfase maior em pesquisa ou desenvolvimento. Assim, o objetivo foi verificar como a experiência com parceiros repetidos e diversificados pode potencializar as alianças estratégicas de P\&D, que tenham maior ênfase em pesquisa ou em desenvolvimento. A pesquisa qualitativa ocorreu mediante a realização de dez entrevistas. Para análise dos dados, foram utilizadas a triangulação de dados e a análise de conteúdo. Três alianças estratégicas formadas entre a EMBRAPA e os parceiros externos constituíram o corpus de análise. Concluiu-se que as instituições envolvidas em alianças, por meio da experiência com repetidos parceiros, potencializaram a CR em alianças com foco em atividades de desenvolvimento e que a experiência com parceiros múltiplos potencializou a CR em alianças com foco em atividades de pesquisa.

Palavras-chave: Capacidade relacional; Alianças Estratégicas de P\&D; Experiência. 


\begin{abstract}
Institutions consider R\&D strategic alliances an alternative way of generating innovation. Among the capacities that can contribute to alliance success is one called relational (RC), that is, a strategic alliance management construct with research gaps that have not yet been verified empirically investigated, such as whether experience with repeated or diversified partners can potentiate, in a distinct way, R\&D alliances that have greater emphasis on research or development. Thus, the objective of this study is to verify how experience with repeated and diversified partners can potentiate the strategic R\&D alliances that have a greater emphasis on research or development. The qualitative research was based on ten interviews. Data triangulation and content analysis were used to analyze the data. Three strategic alliances established between EMBRAPA and external partners constituted the corpus of analysis. It was concluded that the institutions involved in alliances, through experience with repeated partners, potentiated the RC in alliances focused on development activities, while that experience with multiple partners potentiated RC in alliances with focus on research activities.
\end{abstract}

Keywords: Relational Capacity; R\&D Strategic Alliances; Experience.

\title{
RESUMEN
}

Alianzas estratégicas de P\&D son consideradas una alternativa a las instituciones para generar innovaciones. Entre las capacidades que pueden contribuir para el éxito de una alianza está la relacional (CR), esto es, un constructo de gestión estratégica de alianzas con espacios de investigación todavía no verificadas empíricamente, tal como si la experiencia con socios repetidos o diversificados potencializa de forma diferente alianzas que poseen énfasis mayor en investigación o desarrollo. Así, el objetivo fue verificar como la experiencia con socios repetidos y diversificados puede potencializar las alianzas estratégicas de P\&D, que tengan mayor énfasis en investigación 0 en desarrollo. La investigación cualitativa ocurre mediante la realización de diez entrevistas. Para el análisis de los datos, fueron utilizados la triangulación de datos y el análisis de contenido. Tres alianzas estratégicas formadas entre la EMBRAPA y los socios externos constituyeron el corpus del análisis. Se concluye que las instituciones envueltas en alianzas, por medio de la experiencia con repetidos socios, potencializaron la CR en alianzas con foco en actividades de desarrollo y que la experiencia con socios múltiplos potencializo la CR en alianzas con foco en actividades de investigación.

Palabras-clave: Capacidad relacional; Alianzas Estratégicas de P\&D; Experiencia.

\section{INTRODUÇÃO}

Diante do contínuo crescimento populacional, aumento da renda e da expectativa de vida, estima-se que a população mundial seja de nove bilhões, em 2050, assim, a demanda por água, energia, alimentos e fibras será maior, fazendo com que a produção agrícola necessite de aumento de 70\% (EMBRAPA, 2016a). Simultaneamente a esse cenário, prevê-se que as mudanças climáticas provocarão uma queda nos rendimentos das culturas; haverá escassez de água e, ainda, o aumento do número de crianças subnutridas (IFPRI, 2012). Com essa perspectiva, o desenvolvimento de inovações agropecuárias terá um papel importante na ampliação qualificada da produção agrícola e da segurança alimentar, por meio de maquinários eficientes, desenvolvimento de componentes biológicos eficazes e pela criação de cultivares, que permitirão a redução de custos e 0 aumento da produtividade (Vieira \& Silveira, 2011).

Ademais, convém destacar que a agropecuária é um dos setores mais relevantes para a economia brasileira. Isso pode ser comprovado pela representatividade do Produto Interno Bruto (PIB) que, no ano de 2013, correspondeu a 6,55\% do PIB nacional, isto é, aproximadamente R\$ 317 bilhões (CEPEA, 2016); e também pelos números do comércio exterior, já que um terço da produção é exportado (Contini et al., 2012).

A partir da integração e da combinação entre governo, indústria, universidade e sociedade, é possível encontrar e gerar diferentes perspectivas de conhecimento e, consequentemente, inovações voltadas aos interesses da sociedade (Carayannis, Barth, \& Campbell, 2012). O trabalho em conjunto, entre diferentes atores, em que cada um possui missões e foco distintos, desenvolvendo recursos diferentes, é interdependente, sendo capaz de gerar complementação recíproca (Wang \& Zajac, 2007), aumentando, com isso, as chances do desempenho adequado da aliança (George, Zahra, \& Wood, 2002). Tudo dependerá, todavia, da criação de 
relações eficazes entre esses atores, a fim de estabelecer condições essenciais para a promoção desse processo de mudança tecnológica.

Vale adicionar que, com um mercado de mudanças cada vez mais rápidas, a competitividade de uma instituição está cada vez mais relacionada à capacidade de gerar inovações. Novos conhecimentos, produtos, processos, métodos, assim como o aperfeiçoamento dos já existentes, devem ser trazidos ao mercado com grande rapidez, flexibilidade e confiabilidade (Feller et al., 2013). Assim, as alianças estratégicas têm sido consideradas uma alternativa para a realização da Pesquisa e Desenvolvimento (P\&D) e geração de inovação, haja vista a possibilidade de complementação de recursos (Dyer \& Singh, 1998), acesso a novos mercados e redução de custos (Ahuja, 2000).

O desempenho das alianças, todavia, dependerá da capacidade da instituição em adquirir habilidades, trocar continuamente informações e aprendizados, criar estruturas e gerenciar conflitos, o que estabelecerá a confiança mútua entre as partes e, por conseguinte, a geração de valor, denominada capacidade relacional (CR) (Yan, Zhang, \& Zeng, 2010), isto é, um construto de gestão estratégica de alianças com lacunas de pesquisa ainda não verificadas empiricamente (Zollo, Reuer, \& Singh, 2002; Khanna, Gulati, \& Nohria, 1998), tal como se a experiência com parceiros repetidos ou diversificados potencializasse de forma distinta alianças que possuam ênfase maior em pesquisa ou desenvolvimento.

Vale enfatizar que a CR é formada por uma construção multidimensional, baseada em rotinas e processos corporativos, dividida em cinco dimensões: coordenação interorganizacional, transformação da aliança, aprendizagem interorganizacional, proatividade em alianças e portfólio de alianças, e influenciada por dois fatores: a experiência e a estrutura de governança (Schilke \& Goerzen, 2010). Sendo que, neste estudo, será abordado de forma mais específica sobre a experiência.

Destaca-se ainda que o artigo seminal que trouxe a abordagem da CR foi o de Dyer e Singh, em 1998 (Niesten \& Jolink, 2015). Nesse sentido, há estudos que analisam os resultados da interação entre diferentes atores e com distintas finalidades. Entre eles, estão: a análise entre universidade - empresa, com foco no processo de Transferência \& Tecnologia (T\&T) (Chais, 2015); investigação da densidade de alianças estratégicas entre EMBRAPA e empresas privadas com fins de inovação tecnológica (Luciano, 2013); caracterização dos processos de pesquisa em cooperação entre universidade e institutos de pesquisa, em prol do desenvolvimento de inovações tecnológicas voltadas ao setor agropecuário (Dossa \& Segatto, 2010); análise da parceria entre EMBRAPA e empresas privadas para melhorar a eficiência e eficácia da P\&D em soja (De Carli \& Wehrmann, 2007). Nenhuma dessas pesquisas, contudo, até agora, teve como foco avaliar se a experiência com parceiros repetidos ou diversificados potencializa de forma distinta alianças que possuam ênfase maior em pesquisa ou desenvolvimento.

Considerando o importante papel que a inovação agropecuária desempenha no país, e tendo em vista que a formação de alianças estratégicas tem sido cada vez mais utilizada pelas instituições como forma de geração de melhores inovações a partir da capacidade relacional, o objetivo desse estudo é verificar se a experiência com parceiros repetidos e diversificados pode potencializar as alianças estratégicas de P\&D. Para tanto, foi realizado um estudo qualitativo de natureza exploratória, a partir de estudo de caso com três alianças estratégicas de P\&D celebradas entre a Empresa Brasileira de Pesquisa Agropecuária (EMBRAPA) e parceiros externos e que geraram inovações de relevância social, econômica ou ambiental nos últimos 15 anos.

Cabe especificar que a EMBRAPA foi selecionada como unidade de análise por atender os seguintes critérios: a) é reconhecida como um dos principais atores da pesquisa agropecuária brasileira; b) possui experiência na formação de alianças para o desenvolvimento de inovações agropecuárias; e c) possui evidências de $C R$, pois promove integração e interações entre os diferentes atores do Sistema Nacional de Pesquisa Agropecuária (SNPA), incluindo organizações com fins lucrativos (empresas, cooperativas, institutos de pesquisa privados) e sem esses fins (universidades públicas, institutos de pesquisa públicos e organizações sociais).

Quanto às principais contribuições da presente pesquisa para o avanço do conhecimento, está relacionada à experiência (diversidade e reincidência). Foi possível constatar que a repetição de parceiros potencializa, de fato, a CR em alianças cuja ênfase é o desenvolvimento. Por outro lado, em alianças de P\&D, cuja ênfase é a pesquisa, é a experiência com maior diversidade de parceiros de diferentes naturezas (cooperativa, indústria, instituto de pesquisa, agricultor) que potencializa a CR. Sobre os potenciais desdobramentos práticos do estudo para a gestão de alianças estratégicas de $\mathrm{P} \& \mathrm{D}$, orienta aos gestores quanto à importância na seleção de parceiros, sendo que devem ser priorizados parceiros reincidentes. Quando a ênfase da aliança está relacionada às atividades de pesquisa, a busca de parceiros diversificados potencializa a $C R$, contribuindo para alcançar os objetivos das alianças. 
0 artigo está estruturado da seguinte forma: inicia com o referencial teórico, posteriormente são apresentados os procedimentos metodológicos da pesquisa. Em seguida, são realizadas a análise e a discussão dos resultados. Por fim, são apresentadas as considerações do estudo.

\section{INOVAÇÃO, P\&D E ALIANÇAS ESTRATÉGICAS}

O mercado tem sido cada vez mais impactado por uma economia complexa, rápidas mudanças tecnológicas, grande variedade de produtos e exigência de alto nível de especialização (Hitt, Ireland, \& Lee, 2000). A alta velocidade influencia o processo produtivo, reduzindo o ciclo de vida dos produtos e, consequentemente, 0 tempo que as empresas têm para a recuperação de seus investimentos (Narula \& Hagedoorn, 1999). Nesse contexto, a inovação é considerada como uma ferramenta essencial para aumentar a demanda por produtos e serviços, reduzir custos (OECD, 2005) e, ainda, melhorar o desempenho competitivo no mercado (Ireland \& Webb, 2007).

O desenvolvimento de qualquer inovação exige alto investimento em recursos de P\&D (Lin et al., 2016), haja vista seu crucial papel, tanto para gerar ideias inventivas, quanto para auxiliar o processo inovador, em todas as suas etapas, inclusive para resolver problemas que, eventualmente, possam surgir (OCDE, 2013). O Manual de Frascati (OCDE, 2013, p. 38) define P\&D como sendo a "inclusão do trabalho criativo empregado de forma sistemática, com o objetivo de aumentar o volume de conhecimentos, abrangendo o conhecimento do homem, da cultura e da sociedade, bem como a utilização desses conhecimentos para novas aplicações". Assim, pesquisas básicas e aplicadas, por meio de estudos teóricos ou práticos, bem como o desenvolvimento experimental, compõem a P\&D.

A pesquisa básica visa à obtenção de novos conhecimentos, por meio de estudos teóricos ou práticos. Promovida, geralmente, por Instituições de Ensino Superior e pelo setor público, a fim de elaborar e testar hipóteses, formular teorias e leis, ela utiliza a observação dos casos empíricos e de fenômenos. Sem uso específico determinado, não há, por meio dela, qualquer retorno financeiro ou social; seus resultados são, em geral, revertidos em publicações científicas, sendo que o conhecimento é disseminado ao público de interesse (OCDE, 2013).

A pesquisa aplicada, igualmente desenvolvida por intermédio de estudos teóricos ou práticos, contudo, utiliza e aprofunda os conhecimentos decorrentes da pesquisa básica, a fim de encontrar soluções para problemas específicos ou, ainda, para atender a uma oportunidade que surge. Sua utilidade prática é, portanto, específica. Nesse tipo de pesquisa, os resultados encontrados podem virar patentes ou serem preservados em sigilo (OCDE, 2013).

E, por fim, o Manual de Frascati (OCDE, 2013, p. 101) conceitua o desenvolvimento experimental como sendo aquele que "consiste em trabalhos sistemáticos baseados nos conhecimentos existentes obtidos pela pesquisa e/ou experiência prática, tendo em vista a fabricação de novos materiais, sistemas e serviços ou para melhorar os já existentes em P\&D". Tal desenvolvimento promove testes prévios e avaliações finais, a fim de tornar possível a utilização do que foi criado (OCDE, 2013).

Historicamente, verifica-se que as empresas desenvolviam P\&D para a geração de inovações por meio da integração vertical, com fins de criação de seus próprios produtos, fazendo, posterioremente, sua distribuição (Chesbrough, 2006). Essa forma de atuação, todavia, foi se tornando mais difícil, devido aos produtos complexos e ao alto valor de investimento exigido para manter as capacidades técnicas necessárias ao seu lançamento no mercado (Philbin et al., 2014). Assim, a saída tem sido a busca de canais externos para a obtenção ou geração de inovação. Uma das soluções é por meio da inovação aberta, em que se buscam conhecimento e recursos externos para desenvolvimento de P\&D em conjunto (Chesbrough, 2006), podendo se dar por meio de alianças estratégicas, as quais se referem a ligações entre instituições (Kale, Dyer, \& Singh, 2002), que se unem para ter acesso ou desenvolvimento de recursos, conhecimento, know-how, etc. (Ortiz-De-Urbina-Criado, Montoro-Sánchez, \& MoraValentín, 2014).

Kale et al. (2002, p. 748) definem alianças estratégicas como "ligações entre as empresas iniciadas de forma independente que envolvem intercâmbio, partilha, ou co-desenvolvimento de tecnologias, produtos ou serviços". As alianças estratégicas podem ser analisadas a partir de diferentes teorias, dentre elas, a da Visão Baseada em Recurso (VBR) e a institucional.

A VBR postula que, entre as principais motivações que levam à formação de alianças estratégicas, está a possibilidade de as empresas conquistarem vantagens competitivas por meio do acesso a recursos 
idiossincráticos dos parceiros ou pelo desenvolvimento de competências (Barney, 1991) tácitas (Das \& Teng, 2000). Os recursos podem ser divididos entre tangíveis, quando se tratam de recursos financeiros e físicos; intangíveis, que abrangem tecnologia, reputação e recursos organizacionais; e, por fim, humanos, que estão relacionados às especialidades dos empregados, treinamento e cultura (Grant, 1991). Outra motivação é a possibilidade de aumento da aprendizagem organizacional, o que leva ao desenvolvimento de conhecimentos críticos e diversificados, por meio de novas ideias ou diferentes formas de realizar negócios (Gulati, 1998; Hamel, 1991).

A teoria institucional fundamenta que a formação de alianças estratégicas se dá a partir de pressões exercidas por uma organização sobre outras, das quais dependem, ou por expectativas culturais, a fim de que regras, normas e valores similares sejam adotados dentro de um cenário comum (Dimaggio \& Powell, 2000), havendo a aquisição de legitimidade social e 0 aumento das chances de permanência ativa no mercado (Meyer \& Rowan, 1977). Nesse sentido, alianças podem ser formadas com o objetivo de atender às pressões que surgem a partir: a) do sistema regulatório: pressões para que as empresas sigam regras, regulamentos e normas (Oliver, 1991); b) das normas da indústria: pressões que empresas ou concorrentes de um mesmo setor exercem sobre outras empresas, para que busquem o aperfeiçoamento de suas operações; ou a exigência da adoção de códigos ou padrões regulatórios, de modo a tornar a indústria mais legítima (Etzion, 2007); c) grupos da comunidade motivados por pressões exercidas por ONGs ambientais e grupos sociais, devido à preocupação com 0 aumento da destruição ambiental (ativismo e ações judiciais) (Delmas \& Toffel, 2004).

Por sua vez, a teoria de custo de transação ressalta a importância da confiança e das relações interpessoais das alianças (Gulati, 1995; Zaheer, Mcevily, \& Perrone, 1998). Gulati e Gargiulo (1999) afirmam que 0 estreitamento dos laços entre os parceiros favorece o fluxo de aprendizagem de competência e confiança: "A confiança faz com que diminuam os custos de contratação e transação, melhorando retorno que ambas as partes possam obter desse relacionamento" (Khanna, Gulati, \& Nohria, 1998, p. 208). A aproximação, por conseguinte, auxilia na construção e na criação de alianças ainda maiores, gerando benefícios por meio da sinergia, a fim de melhorar o desempenho mútuo (Yan, Zhang, \& Zeng, 2010).

Portanto, a formação de alianças não é um processo simples, sendo que diversos estudos apontam alto índice de insucesso (Arino \& De La Torre, 1998; Koza \& Lewin, 2000). A CR tem sido considerada uma capacidade que, quando desenvolvida pelos parceiros, aumenta as chances de melhorar o desempenho das alianças com 0 propósito de contribuir para o alcance dos objetivos dos atores da aliança (Schilke \& Gorzen, 2010), garantindo 0 desempenho satisfatório entre eles (Yan, Zhang, \& Zeng, 2010). Ela possibilita, ainda, mais equilíbrio à formação de alianças e à proteção de ativos, uma vez que diminui as chances de haver comportamentos oportunistas da incorporação de conhecimento de forma unilateral e do roubo de informações (Kale, Singh, \& Perlmutter, 2000).

Por fim, a literatura indica que o desempenho das alianças pode ser mensurado a partir de diferentes perspectivas: (a) se os objetivos traçados no início da parceria foram alcançados ou não (Brockhoff \& Teichert, 1995; Phillips, Lawrence, \& Hardy, 2000); (b) analisando-se a estabilidade, a constância, continuidade e a evolução da relação com o passar do tempo (Cyert \& Goodman, 1997); (c) pelo grau de satisfação dos parceiros (MOHR; SPEKMAN, 1994); (d) melhoria da posição competitiva da empresa ou aquisição de novas habilidades do parceiro, após a formação da aliança (Draulans Et Al., 2003; Heimeriks \& Duysters, 2007; Heimeriks, Klijn, \& Reuer, 2009; Kale \& Singh, 2007; Schilke \& Goerzen, 2010; Schreiner, Kale, \& Corsten, 2009; Zollo, Reuer, \& Singh, 2002); (e) ganhos financeiros, lucros, vendas ou retorno do mercado de ações (Anand \& Khanna, 2000; Lambe, Spekman, \& Hunt, 2002); (f) inovações geradas (Anderson, Benavides-Espinosa, \& Mohedano-Suanes 2011; Cui \& O'connor, 2012); (g) patentes geradas a partir do resultado de alianças, quando duas ou mais empresas compartilham os direitos de propriedade (Hagedoorn, 2003).

\section{CAPACIDADE RELACIONAL}

O artigo seminal, desenvolvido por Dyer e Singh (1998), discorre que, por meio da CR, era possível a geração de rendas relacionais, acesso a recursos complementares e compartilhar conhecimentos com os parceiros de alianças. Definições similares e complementares foram sendo apresentadadas ao longo do tempo, como sendo a "capacidade de integrar, construir e reconfigurar um conjunto de habilidades, ativos e rotinas que fornecem os recursos base para lidar com a mudança ambientes" (Donada, Nogatchewsky, \& Pezet, 2016, p. 3) ou, ainda, competências técnicas e interpessoais, que são utilizadas no gerenciamento das parcerias (Costa, Porto, \& Silva, 2012). 
A CR é um tipo de capacidade dinâmica, em que uma instituição busca, por meio de rotinas organizacionais, criar, expandir ou transformar a base de recursos (Helfat et al., 2009). Considerando estes fundamentos, o modelo teórico desenvolvido com base em Schilke e Goerzen é multidimensional, baseado em rotinas e processos dinâmicos, dividido em cinco dimensões: coordenação interorganizacional, transformação da aliança, aprendizagem interorganizacional, proatividade em alianças e portfólio de alianças.

A coordenação interorganizacional está relacionada às rotinas e aos processos que possibilitam governar a aliança de forma eficiente (Kumar \& Nti, 1998); a aprendizagem organizacional refere-se à capacidade que a empresa possui em obter, integrar, transformar e explorar os recursos provenientes da aliança, a fim de aprimorar o desempenho no mercado (Zahra \& George, 2002); a proatividade diz respeito às rotinas e aos processos que levam a empresa a tomar a iniciativa de formar alianças, identificando parceiros em potencial para complementação de recursos (Sarkar, Aulakh, \& Madhok, 2009); a transformação das alianças refere-se a rotinas e processos que contribuem para a realização de modificações na aliança e de ajustes necessários à potencialização de seu desempenho (Kale, Dyer, \& Singh, 2002); e o portfólio de aliança na coordenação de todas as alianças estratégicas de uma organização, por meio das rotinas relacionadas à integração de P\&D de uma unidade de negócios, a fim de identificar interdependências, evitar a realização de atividades duplicadas, desenvolver sinergia entre as alianças (Hoffmann, 2005) e reduzir conflitos (Parise \& Casher, 2003).

Schilke e Goerzen (2010) destacam que a CR é, ainda, influenciada, principalmente, por dois fatores: a estrutura da aliança e a experiência. Empresas que detêm uma estrutura de governança voltada à administração das alianças conseguem desenvolver meios para geri-las de forma mais eficiente (Heimeriks \& Duysters, 2007; Kale \& Singh, 2007).

Em recentes pesquisas, Alves (2015) reorganizou e agrupou, por semelhança, as dimensões de capacidades relacionais, a partir de cinco estudos, bem como desenvolveu novas dimensões do constructo (coordenação, cultura, conhecimento, tecnologia e coadaptação). A dimensão de coordenação está relacionada à capacidade de gestão da parceria, uma vez que administra os recursos, de modo a torná-la mais eficiente, lucrativa, geradora de produção e, com base no estudo de Schilke e Goerzen (2010), capaz de evitar a duplicação de atividades e de reduzir conflitos. A dimensão cultural se refere à capacidade da empresa em se relacionar com parceiros de diferentes culturas, lidando adequadamente com questões emocionais, sociais e conflitos que, eventualmente, possam surgir (Ngugi, Johnsen, \& Erdélyi, 2010). A terceira dimensão é a do conhecimento, relacionada à capacidade de gerar, incorporar, usar e administrar os saberes advindos da parceria. Ressalta-se, nessa dimensão, a questão da aprendizagem e das rotinas e dos processos presentes na transferência e nos resultados do conhecimento (Johnsen \& Ford, 2006; Mcgrath, 2008; Ngugi, Johnsen, \& Erdélyi, 2010; Schilke \& Goerzen, 2010). A dimensão tecnológica reúne a coinovação (Mcgrath, 2008) e a tecnologia (Johnsen \& Ford, 2006; Ngugi, Johnsen, \& Erdélyi, 2010), que se referem à competência de desenvolvimento, integração, expansão, inovação tecnológica e absorção do conhecimento dos parceiros. A quinta e última dimensão é a de coadaptação, que está voltada à capacidade de adequar recursos ou meios de funcionamento, em função de ampliar os benefícios da parceria, seja por meio da criação de novos produtos ou soluções, seja por relacionamentos mais adequados (Mcgrath, 2008; Sarkar, Aulakh, \& Madhok, 2009; Schilke \& Goerzen, 2010).

Por fim, cabe enfatizar que o gerenciamento de uma aliança demanda capacidades relacionais que nem sempre são fáceis de adquirir e manter (Ireland, Hitt, \& Vaidyanath, 2002). Donada et al. (2016) realizaram estudo longitudinal, buscando compreender como a capacidade é construída e de que maneira ela é capaz de evoluir em um ambiente de mudança ao longo do tempo. Os autores encontraram três fases. A primeira delas é quando a empresa compreende suas fraquezas e percebe a necessidade de recursos complementares, estímulo este gerado, normalmente, por fatores externos. Assim, desenvolve-se um período de aprendizagem e de análise do conhecimento interno, visto que ainda não estão estabelecidas as intenções estratégicas a serem utilizadas. A segunda fase é mais operacional, pois há uma mobilização de fontes externas e facilitadores internos, de modo a desenvolver e coordenar as capacidades relacionais para a avaliação e seleção de futuros parceiros. Por fim, a terceira fase é mais estratégica, já que é o momento do surgimento das primeiras rendas relacionais e da realização das projeções de longo prazo. Nessa fase, os facilitadores internos desempenham uma papel importante, visando integrar habilidades, ativos e rotinas resultantes da aliança à estratégia da empresa, a fim de que sejam aplicados, na prática, para constituir uma governança relacional eficaz.

\section{PROPOSIÇÕES DE PESQUISA}


A experiência no estabelecimento de alianças contribui para a aprendizagem (Herriott, Levinthal, \& March, 1985; Levitt \& March, 1988), pois, com o tempo, permite o desenvolvimento da capacidade para identificar parceiros, iniciar e gerenciar parcerias e efetuar os ajustes necessários para que se consiga atingir benefícios colaborativos tangíveis e intangíveis (Heimeriks, Duysters, \& Vanhaverbeke, 2007). Isso se dá porque ela terá "maior consciência do funcionamento das regras, rotinas e procedimento que cada ator deve seguir" (Khanna, Gulati, \& Nohria, 1998, p. 208), podendo, facilmente, gerenciar acordos e desenvolver a CR (Heimeriks \& Duysters, 2007; Kale \& Singh, 2007). Assim, quanto maior o número de experiências anteriores, seja com parceiros específicos ou de forma geral, maior será o aprendizado em alianças estratégicas, sendo um dos fatores que levam ao bom desempenho da aliança (Shakeri \& Radfar, 2017).

Quando uma instituição possui experiência em alianças com atores de distintas naturezas, é possível gerar invenções com maior significado técnico e de mais fácil introdução no mercado (Walsh, Lee, \& Nagaoka, 2016). Isso porque a colaboração multidisciplinar permite a complementação de recursos e conhecimentos, como no caso de institutos de pesquisa (conhecimento científico) e indústrias (conhecimento de mercado/industrial) (Du, Leten, \& Vanhaverbeke, 2014). Às empresas/indústrias, possibilita acesso ao conhecimento científico tácito (Bishop, D'este, \& Neely, 2011), ao codificado, isto é, àquele que ainda não foi publicado (Fabrizio, 2009) e, também, às novas tecnologias - ou ao refinamento das tecnologias existentes (Perkmann \& Walsh, 2007). Por parte das organizações de pesquisa, tal aliança é igualmente vantajosa porque permite um entendimento melhor de como o conhecimento científico é utilizado nas atividades comerciais.

Assim, a experiência com distintos atores mostra-se benéfica, isso porque, de forma específica, há maior sensibilidade na prospecção de informações e conhecimentos de múltiplas fontes externas. Sendo assim, tem-se a expectativa de que a variação de parceiros pode ser oportuna em alianças relacionadas à pesquisa de longo prazo, de novos conhecimentos, em prol do avanço da ciência e da sociedade, formulando-se assim a seguinte proposição:

Proposição 1: Quando o propósito é a pesquisa de longo prazo, a experiência no estabelecimento de alianças estratégicas, com diferentes parceiros, potencializa a $\mathrm{CR}$.

Por outro lado, de acordo com Niesten e Jolink (2015), quando há repetição na formação de alianças entre os mesmos parceiros, adquire-se conhecimento de ambos os lados, de diferentes formas, passível de ser capturado, compartilhado, armazenado e utilizado, futuramente, em estruturas interorganizacionais com os mesmos parceiros. Quanto maior a repetição dos parceiros na formação de alianças, mais refinada se torna essa relação, pois padrões e rotinas vão sendo estabelecidas e refinadas, facilitando a troca de informação e know-how entre os parceiros, os quais conseguem estabelecer mais facilmente a tarefa que cada um deve executar (Zollo, Reuer, \& Singh, 2002).

Além disso, a reincidência de parceiro possibilita ter um conhecimento mais aprofundado sobre cultura, forma de gerenciamento, pontos fortes e fracos, modo de agir, crenças das partes envolvidas, o que contribui para a eficácia de futuros acordos e para o fortalecimento da aliança entre parceiros repetidos (Zollo, Reuer, \& Singh, 2002). Possibilita, ainda, elaborar contratos mais detalhados e com menores custos, pois já se tem conhecimento prévio do parceiro (Ryall \& Sampson, 2006). Ademais, a repetição de parceiros na formação de alianças gera, também, maior agilidade na condução de rotinas e processos, pois permite maior conhecimento sobre cultura, crenças e forma de atuação do parceiro, facilitando o gerenciamento da parceria e aumentando as chances de sua eficácia (Zollo, Reuer, \& Singh, 2002; Khanna, Gulati, \& Nohria, 1998). Acredita-se, portanto, que a repetição de parcerios pode ser oportuna em alianças relacionadas ao desenvolvimento de soluções imediatas para o mercado. Assim, se estabelece a seguinte proposição:

Proposição 2: Quando o propósito é o desenvolvimento de curto e médio prazo, a experiência no estabelecimento de alianças estratégicas, com os mesmos parceiros, potencializa a CR.

\section{METODOLOGIA}

Para atingir o objetivo geral desta pesquisa, foi realizada uma pesquisa de natureza qualitativa, sendo que 0 ambiente do fenômeno estudado foi utilizado como fonte de dados, e o pesquisador, como um instrumento fundamental para a coleta desses dados, seleção, verificação e interpretação das informações (Creswell, 2017). A abordagem foi a exploratória, por meio de um processo de interação entre o pesquisador, os participantes e os locais estudados, visando modificar ou clarificar conceitos (Marconi et al., 2006). O método utilizado foi o estudo de caso, uma vez que não havia domínio sobre o fenômeno estudado, permitindo, assim, verificar, ligar e comparar as 
informações obtidas (conhecimento prático) e compará-las com as proposições do estudo (conhecimento teórico) (Godoy, 1995).

Para a investigação do problema, a unidade de análise selecionada foi a EMBRAPA. Para tal, foram identificadas três alianças para serem analisadas, a partir dos seguintes fundamentos: alianças estratégicas de P\&D que geraram inovações de relevância social, econômica ou ambiental; e alianças estratégicas que tenham sido celebradas nos últimos 15 anos. A escolha do período se refere ao fato de que, como a EMBRAPA tem em seu histórico o desenvolvimento de cultivares, para obter uma nova cultivar, leva-se em média 12 anos, optou-se por utilizar esse período para que alianças de P\&D, com foco em pesquisa de longo prazo, pudessem ser incluídas na pesquisa.

Realizou-se consulta no site da EMBRAPA na categoria de produtos, processos e serviços (https://www.embrapa.br/produtos-processos-e-servicos) sobre as soluções tecnológicas desenvolvidas pela empresa. Ao aplicar o filtro para o período compreendido entre 2002 a 2017, o site apresenta um total de 1.794 tecnologias. Esse resultado abrange tecnologias que foram geradas somente pela EMBRAPA e também entre a EMBRAPA e parceiros externos. Posteriormente, houve consulta acerca das cultivares registradas em nome da EMBRAPA, no Registro Nacional de Cultivares (RNC), pelo site (http://www.agricultura.gov.br/guia-de-servicos/registro-nacional-decultivares-rnc). Em janeiro de 2017, a EMBRAPA possuía aproximadamente 1.580 cultivares registradas. E, por fim, buscaram-se, no site do Instituto Nacional da Propriedade Industrial (http://www.inpi.gov.br/), as patentes já registradas ou com pedido de registro pela EMBRAPA.

Considerando as alianças estratégicas formadas pela EMBRAPA com parceiros externos para 0 desenvolvimento de tecnologias, a partir dos critérios anteriormente mencionados, três alianças de P\&D foram selecionadas de forma intencional para a realização do estudo, que são: a) Embalagens anatômicas para frutas, desenvolvidas entre a Unidade da EMBRAPA Agroindústria de Alimentos e institutos de pesquisa públicos (IMA e INT), inovação com benefícios ambientais, econômicos e sociais, que resultou em 39 patentes; b) Cultivar de Cevada - BRS Quaranta, desenvolvida entre a Unidade da EMBRAPA Trigo, Fundação de Pesquisa (FAPA) e empresa (AmBev), inovação que traz benefício econômico e social. Além disso, $90 \%$ das cultivares de cevada cervejeira no mercado são desenvolvidas pela EMBRAPA; e c) INOVA-Bti - inseticida biológico, desenvolvido entre a Unidade da EMBRAPA Recursos Genéticos e Biotecnologia, um instituto de pesquisa privada (IMAmt) e cooperativa (Comdeagro). Inovação de grande benefício social, uma vez que permite a redução da proliferação do mosquito Aedes aegypti, transmissor dos vírus da dengue, chikungunya e zika.

Em relação à coleta de dados, foram realizadas 10 entrevistas: 3 com os chefes de Transferência de Tecnologia (T\&T) das Unidades cujas inovações foram selecionadas; 1 com o chefe-geral da Unidade de Recursos Genéticos e Biológicos (CENARGEN); e 6 com pesquisadores que tiveram a participação direta tanto de atividades de P\&D e também na coordenação das alianças selecionadas, sendo 3 da EMBRAPA e 3 das instituições parceiras que atuaram diretamente nas alianças para desenvolvimento das tecnologias nas Unidades. Com exceção da entrevista com o pesquisador da FAPA, realizada via Skype, todas as outras aconteceram presencialmente. Entrevistou-se ainda, a Coordenadora de Apoio à Inovação e Propriedade Intelectual da EMBRAPA, por telefone, a fim de identificar as características relacionadas à formação de alianças da EMBRAPA e a evolução da formalização. Buscou-se, ainda, entender as questões de propriedade intelectual e o tempo de duração das alianças com diferentes objetivos. Para a realização das entrevistas, foi utilizado um roteiro semiestruturado, seguindo modelo de Schilke e Goezen (2010) e todas as entrevistas foram gravadas, totalizando seis horas e quarenta e oito minutos de gravação.

Zamberlan et al. (2014) sugerem que o mais adequado é buscar outras fontes para ratificar os dados coletados pela entrevista. A observação, nesse sentido, também foi utilizada por este estudo, pois possibilita ao pesquisador identificar e obter informações decorrentes, sendo que informações do ambiente e expressões, comportamentos, fatos e sentidos dos indivíduos são coletados culminantemente no momento das entrevistas in loco (Zamberlan et al., 2014; Godoy, 1995). Essas informações foram registradas em diário de campo.

Além disso, foram obtidos dados secundários nos sites da EMBRAPA e dos seus parceiros, havendo, também, a consulta de cultivares registradas em nome da EMBRAPA, no RNC e levantamento e confirmação de informações de patentes por meio de pesquisa no site do Instituto Nacional da Propriedade Industrial (http://www.inpi.gov.br/) e realizou-se a análise de documentos como contratos, projetos e fôlderes, arquivos, relatórios, atas de reuniões, regulamentos, jornais e revistas. Com as distintas fontes de dados (entrevistas semiestruturadas, documentos e observação não participante), foi possível analisar os tópicos a partir de diferentes pontos de vista e da comparação entre eles, a fim de ter conclusões mais consistentes, procedimento esse denominado de triangulação (Zamberlan et al., 2014). As informações coletadas por meio das entrevistas foram estudadas pela técnica de análise de conteúdo, possibilitando a organização e a classificação das informações de 
forma quantitativa, a partir de categorias sistematizadas, o que, por sua vez, auxilia na redução dos dados coletados, garantindo maior precisão das informações (Marconi et al., 2006). No Figura 1 é possível verificar a síntese do delineamento metodológico.

\begin{tabular}{|l|l|}
\hline Delineamento Metodológico \\
\hline Natureza da pesquisa & Qualitativa (CRESWELL, 2017). \\
\hline $\begin{array}{l}\text { Abordagem } \\
\text { metodológica }\end{array}$ & Exploratória (GODOY, 1995). \\
\hline Método & Estudo de caso (GODOY, 1995). \\
\hline Unidades de análise & 03 alianças estratégicas de P\&D formadas entre EMBRAPA e parceiros externos. \\
\hline \multirow{2}{*}{$\begin{array}{l}\text { Procedimento de coleta } \\
\text { de dados }\end{array}$} & Realização de entrevista semiestruturada (ZAMBERLAN et al., 2014). \\
\cline { 2 - 3 } & $\begin{array}{l}\text { Análise documental. Análise de contratos, projetos, fôlderes e sites, uso de diários e } \\
\text { observação (ZAMBERLAN et al., 2014). }\end{array}$ \\
\hline $\begin{array}{l}\text { Instrumentos de coleta } \\
\text { de dados }\end{array}$ & Roteiro de entrevista semiestruturada (GIL, 2008). \\
\cline { 2 - 2 } Análise dos dados & $\begin{array}{l}\text { Análise de contratos, fôlderes e sites (ZAMBERLAN et al., 2014). } \\
\text { 2006). }\end{array}$ \\
\hline \multirow{2}{*}{$\begin{array}{l}\text { Perguntas de pesque e estratégia analítica baseada em proposições teóricas (MARCONI et al., } \\
\text { que orientaram o roteiro } \\
\text { de entrevista e o roteiro } \\
\text { de análise documental }\end{array}$} & $\begin{array}{l}\text { 1. A prática continuada (experiência) no estabelecimento de parcerias para a realização de } \\
\text { gestão estratégica das parcerias firmadas para a inovação? }\end{array}$ \\
\hline $\begin{array}{l}\text { 2. É comum haver a repetição de parcerias com o mesmo parceiro? Principalmente para a } \\
\text { realização de Pesquisa ou Desenvolvimento? Por qual motivo? }\end{array}$ \\
\hline \multirow{2}{*}{ Perfil dos entrevistados } & $\begin{array}{l}\text { Chefe-geral da Unidade de Recursos Genéticos e Biológicos (CENARGEN); e seis com } \\
\text { pesquisadores, sendo três da EMBRAPA e três das instituições parceiras que atuaram } \\
\text { diretamente nas alianças para desenvolvimento das tecnologias nas Unidades. }\end{array}$ \\
\hline
\end{tabular}

Figura 1: Delineamento Metodológico.

Fonte: Elaboração própria (2017).

\section{ANÁLISE DOS RESULTADOS}

Neste capítulo, serão apresentados os resultados da análise das três alianças estratégicas celebradas entre a EMBRAPA e os parceiros externos, as quais resultaram em três inovações: embalagens anatômicas para frutas, cultivar de cevada - BRS Quaranta e INOVA-Bti, inseticida biológico, cada uma sendo detalhada a seguir. Convém destacar que, na EMBRAPA, as alianças para desenvolvimento, consideradas de curto e médio prazo, têm a duração aproximada de 12 a 60 meses; enquanto as alianças para pesquisas para geração de novas cultivares podem levar em torno de 10 a 12 anos, sendo consideradas como de longo prazo.

\subsection{Embalagens anatômicas para frutas (Aliança 1)}

As embalagens anatômicas para frutas foram desenvolvidas a partir de aliança estratégica celebrada entre a EMBRAPA Agroindústria de Alimentos, Instituto Nacional de Tecnologia (INT); Instituto de Macromoléculas (IMA), da Universidade Federal do Rio de Janeiro (UFRJ) e a Fundação Coordenação de Projetos, Pesquisas e Estudos Tecnológicos (COPPETEC), sendo que esta participou das atividades de coordenação e administrativa.

A EMBRAPA Agroindústria de Alimentos, localizada na cidade do Rio de Janeiro, é uma das Unidades Temáticas Descentralizadas da EMBRAPA. Instituída no ano de 1973, seu objetivo é encontrar, por meio de pesquisas, desenvolvimento e inovações direcionadas à agroindústria de alimentos, diferentes matérias-primas ou distintos usos na agropecuária, bem como desenvolver técnicas que aumentem a durabilidade de alimentos, mantendo a qualidade e a segurança, contribuindo, também, para o aumento da competitividade e da sustentabilidade do setor agroindustrial. Dentre os laboratórios que a Unidade possui, está o de pós-colheita, no qual são realizadas P\&D direcionadas ao aumento da vida útil e da manutenção da qualidade de frutas e hortaliças in natura e pouco processadas (EMBRAPA, 2017a).

Inaugurado no ano de 1976, o Instituto de Macromoléculas Professora Eloisa Mano (IMA-UFRJ), que faz parte da Universidade Federal do Rio de Janeiro (UFRJ), é referência nas áreas de Ciência e Tecnologia de Polímeros, tanto no Brasil quanto na América Latina. Com pesquisas voltadas às áreas da Engenharia (Química, de Produção, Mecânica, de Materiais etc.), Farmacêutica, Química, Biomédica e Médica, seu programa de Strictu Sensu possui o conceito mais alto da Coordenação de Aperfeiçoamento de Pessoal de Nível Superior

Revista Alcance - Eletrônica - vol. 25 - n. 3 - Set./Dez. 2018 
(CAPES). Dentro do IMA, existe o Núcleo de Excelência em Reciclagem e Desenvolvimento Sustentável (NERDES), que visa ao desenvolvimento de tecnologias com menor impacto ambiental, por meio da redução da utilização de matéria-prima e energia (IMA, 2019).

O Instituto Nacional de Tecnologia (INT) é uma instituição ligada ao Ministério da Ciência, Tecnologia, Inovações e Comunicações (MCTIC), cujo objetivo, desde sua criação, em 1921, é o desenvolvimento de inovações, por meio de pesquisas que possam, posteriormente, ser transferidas ao setor produtivo. Com ampla atuação em várias áreas, entre elas a de Desenho Industrial, as pesquisas desenvolvidas pelo INT são direcionadas a setores como petróleo e gás, energias renováveis, química verde, complexo industrial, saúde, defesa e tecnologias sociais, além de buscar soluções na área de nanoquímica. Detentor de uma equipe especializada e 20 laboratórios, que atendem às normas de qualidade industrial, o INT foi a primeira instituição federal que recebeu o credenciamento pelo Inmetro para certificar produtos (INT, 2019).

A aliança estratégica teve início em fevereiro de 2010 e sua conclusão em 2015 (EMBRAPA, 2017b), a duração, portanto, de médio prazo, conforme considerado pela EMBRAPA. Para o alcance do objetivo aliança, foi necessária a realização de atividades relacionadas à pesquisa aplicada e, sobretudo, ao desenvolvimento.

Para o alcance do objetivo dessa aliança, foi necessária a realização de atividades relacionadas à pesquisa aplicada e, sobretudo, ao desenvolvimento. De acordo com o Manual de Frascati (2013), a pesquisa aplicada utiliza e aprofunda os conhecimentos dos estudos teóricos ou práticos, a fim de encontrar respostas para problemas específicos. Dentre as atividades de pesquisa, estava o levantamento de problemas por parte dos agricultores, o formato e o tamanho das frutas, o período de colheita, etc.

Outra parte da pesquisa estava relacionada à utilização do tipo de fibra mais adequado à mistura ao compósito. Essa atividade estava sob a coordenação do IMA, com o apoio das outras instituições. As atividades de pesquisa do IMA eram: selecionar, tratar e caracterizar rejeitos agrícolas que pudessem ser utilizados nos compósitos polímeros; selecionar os materiais poliméricos mais adequados à preparação dos compósitos, com base nas características físico-químicas e desempenho mecânico; preparar as formulações investigando a quantidade ideal de fibra a ser usada, o tamanho da fibra e a necessidade de adição de outros produtos.

A EMBRAPA atuou como intermediária do setor primário produtivo, fornecendo os resíduos da produção agrícola para serem utilizados como matéria-prima. Além disso, coube a ela, devido ao contato direto com o setor produtivo, o levantamento das necessidades de cada produto e das características apropriadas das embalagens; bem como a concessão de informações sobre as propriedades dos produtos, no que diz respeito à fisiologia pós-colheita, vida útil, dimensões, temperatura e umidade relativa ao armazenamento.

O Manual de Frascati (OCDE, 2013) define desenvolvimento experimental como atividades sistemáticas decorrentes de estudos e práticas realizadas previamente, com o objetivo de produção de novos materiais, sistemas e serviços, ou para aprimorar os já existentes. Sendo assim, ao INT, foram conferidas, sobretudo, as atividades relacionadas ao desenvolvimento dos projetos das embalagens primárias, secundárias e terciárias, no campo do Design, bem como o repasse à sociedade, às indústrias e às comunidades dos modelos, métodos, processos e conhecimentos necessários à fabricação em escala das embalagens projetadas.

Para a EMBRAPA, as embalagens são classificadas como inovações de processo agroindustrial. A inovação de processo é caracterizada por alteração técnica ou criação de métodos de produção/entrega de bens ou serviços, cujo resultado é a redução de custos de produção ou melhoria da eficiência (OECD, 2005). As embalagens estudadas, nesse sentido, diferenciam-se das tradicionais por terem uma forma com nichos de distintos tamanhos e formatos, capazes de acomodar o mesmo tipo de fruta, mas com dimensões variadas, o que contribui para a redução de choque entre as unidades, diminuindo os danos ao produto. Acopladas numa espécie de suporte, tais formas, mesmo quando empilhadas, reduzem as injúrias mecânicas às frutas.

Além disso, elas são vazadas, o que permite a troca de gases com 0 ambiente, adiando 0 amadurecimento e prolongando a vida útil do produto. $O$ suporte, ainda, por ser termoinjetado articulado, pode ser fechado, diminuindo o espaço utilizado no transporte de regresso ao produtor, portanto, reduz o impacto, preserva a qualidade e facilita o transporte e o manuseio. As mesmas são consideradas ecologicamente corretas, pois a matéria-prima utilizada é um compósito de polímeros e resíduos de fibras vegetais (que seriam descartados), além de propiciar uma economia de matéria-prima e energia e gerar menor impacto ao meio ambiente (entre 10\% a 30\% a menos do que as demais), haja vista sua maior capacidade de decomposição na natureza.

Além da justificativa ambiental apresentada, há vantagens sociais e econômicas no uso desse tipo de embalagem, em razão da diminuição de perdas (mamão de $25 \%$ para somente $2 \%$ ) e do desperdício. Houve ainda aumento da vida útil do caqui, entre 4 e 6 dias, em comparação com o armazenamento tradicional (caixas de 
madeira). Ademais, essas embalagens geram maior eficiência no trabalho, pois do produtor pode ir diretamente para a comercialização sem ter a necessidade de passar pela casa de embalagens, reduzindo $50 \%$ do tempo gasto no processo (EMBRAPA, 2017c). Assim, quando uma inovação consegue apresentar três benefícios distintos culminante (ambiental, econômico e social), é denominada como uma inovação social, ou seja, tecnologias que resultam em "mudança nas relações sociais, sistemas ou estruturas e; tais mudanças servem para atender a uma necessidade ou objetivo, ou resolver a um problema social relevante" (Van Der Have \& Rubalcaba, 2016, p.10).

\subsection{Cultivar de cevada - BRS (Aliança 2)}

A aliança estratégica de P\&D para o desenvolvimento da cultivar de cevada BRS Quaranta contou com a participação de três instituições: EMBRAPA Trigo, Fundação Agrária de Pesquisa Agropecuária (FAPA) e Companhia de Bebidas da Américas (AmBev).

A Embrapa Trigo é uma das Unidades de Produto da EMBRAPA, localizada na cidade de Passo Fundo, no Rio Grande do Sul. Fundada no ano de 1974, tem como objetivo realizar pesquisas para desenvolvimento de inovações tecnológicas que resultem no aumento dos rendimentos da produção agrícola, principalmente do trigo e das demais culturas de inverno. Esses objetivos são buscados de forma sustentável, preservando os recursos naturais e a biodiversidade (EMBRAPA, 2017d).

Entre os parceiros para o desenvolvimento de cultivares de cevada está a Fundação Agrária de Pesquisa Agropecuária (FAPA). Onze pesquisadores são responsáveis pela P\&D de cultivares e híbrido "milho, soja, cevada, período mais adequado para plantio, fertilidade do solo, densidade de plantas, manejo de doenças e pragas, inovações tecnológicas e maquinário agrícola" (Agrária, 2019a). A FAPA foi fundada pela Cooperativa Agrária, instituída nos anos de 1950, no município de Guarapuava, no estado do Paraná. Trata-se de uma cooperativa agroindustrial que compreende desde a pesquisa até a industrialização. Atualmente, ela possui 600 cooperados e 1.500 colaboradores, tendo um faturamento total, no ano de 2016, de 2,7 bilhões. Assim, 0 objetivo da FAPA é realizar P\&D que respondam às necessidades de produção de seus clientes (cooperados) e de suas unidades de negócios (Agrária, 2019b).

A AmBev surgiu a partir da união de duas cervejarias, Cervejaria Brahma e Companhia, em 1999. Está presente em 19 países, possui 32 cervejarias, 30 marcas de bebidas e duas maltarias no Brasil, sendo uma localizada no município de Passo Fundo (RS) (Ambev, 2019).

A aliança estratégica teve início em 2002, com a assinatura do Contrato de Cooperação Técnica, em 10 de maio de 2002, e lançamento em 2015 (EMBRAPA, 2017e). O período de duração dessa aliança foi de 12 anos, caracterizando-se como de longo prazo.

0 desenvolvimento de novas cultivares de cevada são consideradas inovação de produto, seguindo 0 conceito proposto pela OCDE (2005). Inovação de produto se trata da implantação de um produto ou comercialização de um inexistente, ou de novos usos e combinações de conhecimentos e tecnologias para melhoramento/inserção de outras características em seu funcionamento (OECD, 2005).

A realização da pesquisa para desenvolvimento de cultivares de cevada é realizada em algumas etapas. A primeira fase é a do melhoramento, que dura aproximadamente seis safras (anos), em que são realizadas atividades de desenvolvimento de linhagens, a partir de cruzamentos (hibridações artificiais) e seleção de plantas, em populações segregantes. Na sétima geração, após o emprego de métodos de seleção de espécies autógamas, as plantas já manifestam elevado grau de uniformidade e, sendo colhidas em conjunto (reunião de plantas uniformes), constituem as novas linhagens. As melhores linhagens, selecionadas com base no rendimento de grãos, ciclo e altura, são avaliadas na próxima fase (Minella, 2013).

A próxima fase é a da experimentação, em que são realizadas pesquisas (experimentos) para avaliar 0 desempenho agronômico das linhagens desenvolvidas na fase anterior. Inicialmente, os experimentos são conduzidos na EMBRAPA, denominados como Populações Novas Linhagens (PONL), para avaliação do rendimento de grãos, reação a doenças, classificação comercial e qualidade tecnológica (testes preliminares, de proteínas, principalmente) para conhecimento da aptidão industrial (Minella, 2013).

Depois, confirmando-se o desempenho superior, as melhores linhagens são avaliadas em uma rede de locais, representativos da região, de abrangência do programa de melhoramento (região de indicação das novas cultivares). A rede de experimentos permite determinar o valor de cultivo e uso, denominado Ensaio de Valor de Cultivo e Uso (VCU) (Minella, 2013). O Ensaio de VCU é conduzido por três anos, etapa na qual há a

Revista Alcance - Eletrônica - vol. 25 - n. 3 - Set./Dez. 2018 
participação mais intensa da FAPA na condução dos ensaios, no estado do Paraná (PR) e a participação da AmBev para a condução de ensaios do RS. Quanto mais diversificados forem os ambientes (locais de avaliação) do ensaio, maior confiança haverá sobre a adaptação das linhagens, candidatas a novas cultivares (pois nem sempre uma cultivar que se adapta bem em uma região vai se adaptar em outra).

As principais características da cultivar de cevada Quaranta é o seu alto rendimento, qualidade e é resistente ao oídio. Em decorrência de sua resistência genética, o manejo de doenças da cultivar poderá dispensar, de forma parcial ou total, as aplicações de fungicida para controle do oídio e da mancha reticular. Assim, sua alta produtividade é justificada economicamente pela possibilidade de menor utilização de herbicidas, o que, também, é denominada uma ecoinovação (EMBRAPA, 2017f). A ecoinovação surge em decorrência da combinação de dois desenvolvimentos: 0 ambiental e o econômico, a partir de maior rendimento econômico com redução de impactos ambientais e do uso racional dos recursos naturais. A menor utilização de recursos e energia deve estar presente em todos os ciclos, desde a fase de extração material, produção, distribuição, reutilização, até o momento do descarte (Cella-De-Oliveira \& Munck, 2014).

\subsection{INOVA-Bti - Inseticida Biológico (Aliança 3)}

O INOVA-Bti foi desenvolvido por meio de aliança estratégica entre a EMBRAPA Recursos Genéticos e Biotecnologia (CENARGEN), em parceria com o Instituto Mato-Grossense do Algodão (IMAmt) e a Cooperativa Mista de Desenvolvimento do Agronegócio (Comdeagro) (EMBRAPA, 2017g).

O CENARGEN possui o terceiro maior banco de recursos genéticos do mundo, cuja capacidade de armazenamento é 700 mil amostras (Briones, 2016) e tem atuado amplamente no intercâmbio e na quarentena de germoplasma vegetal, visando ao prosseguimento dos programas de melhoramento genético, sem a introdução e a disseminação de pragas agrícolas (EMBRAPA, 2017h). Vários cultivos estão sendo trabalhados para se ter organismos geneticamente modificados, como soja, milho, algodão e eucalipto; desenvolvendo medicamentos, cultivo in vitro e biofábricas. A biotecnologia, hoje, tem um conceito muito amplo, aplicando-se, praticamente, em quase todos os setores da agropecuária, saúde animal e saúde humana (Entrevista chefe-geral do CENARGEN).

O Instituto Mato-Grossense do Algodão (IMAmt) foi instituído no ano 2007 pela Associação MatoGrossense dos Produtores de Algodão (AMPA), visando ao desenvolvimento e à difusão de novas tecnologias aos associados (IMAMT, 2019). Seu objetivo principal é o Programa de Melhoramento Genético de Algodão, que pretende desenvolver variedades de algodão (convencionais e transgênicas) mais produtivas e com fibras de melhor qualidade, sendo tolerantes às pragas que afetam as plantações de algodão.

Mesmo com o foco principal sendo o algodão, o Instituto possui um programa de melhoramento genético da soja, do sorgo e das oleaginosas (mamona, cártamo e gergelim) (IMAMT, 2019). No final de 2009, foi criada, pela AMPA, a Comdeagro, com o propósito de colocar à disposição dos associados as tecnologias desenvolvidas pelo IMAmt e parceiros, de forma mais ágil e com preço mais acessível, tornando-se, com isso, seu braço comercial (IMAMT, 2019).

A formalização da aliança deu-se por meio da celebração de um Contrato de Cooperação Técnica, firmado em 04 de fevereiro de 2016, sendo que o lançamento aconteceu no mesmo ano (EMBRAPA, 2017g). 0 INOVA-Bti é um bioinseticida que auxilia no controle das larvas do mosquito Aedes aegypti (mata as larvas e não o mosquito), transmissor do vírus da dengue, chikungunya e zika. Ele foi formulado por meio de um princípio ativo de uma bactéria (Bacillus thuringiensis israelenses - Bti), que está presente de forma natural no meio ambiente. 0 INOVA-Bti, não apresenta qualquer risco às pessoas, animais e meio ambiente, podendo ser adicionado a reservatórios de água para o consumo, em locais apropriados para a proliferação, ou ligado a outros meios de controle do mosquito (EMBRAPA, 2017h).

O INOVA-Bti pode ser considerado uma inovação sustentável, isso porque ele é resultado da somatória entre a ecoinovação e a preocupação social. Assim, de acordo com Barbiere et al. (2010, p. 151), inovação sustentável é:

a introdução (produção, assimilação e exploração) de produtos, processos de produção, gestão ou métodos de negócios, novos ou significativamente melhorados, que trazem benefícios econômicos, sociais e ambientais quando comparados com alternativos. 
Dentre as atividades de P\&D, as que mais intensamente foram executadas, estavam relacionadas ao desenvolvimento, isso porque ambas instituições possuíam a expertise relacionadas à pesquisa e foram realizadas atividades de desenvolvimento para realizar as adequações da formulação do produto. Toda pesquisa e conhecimento prévio contribuem para que o desenvolvimento do produto fosse realizado em um curto prazo, ou seja, menos de um ano. Foi possível desenvolver esse produto em pouco tempo, devido à grande expertise que já existia sobre 0 assunto de ambas as partes e à base de formulação disponível, sendo necessária a realização de pesquisa para adequações aos objetivos (Pesquisador entrevistado do IMAmt).

Dentre as atividades de P\&D, estavam: indicação de estirpes (bactérias), otimização do processo de produção das estirpes, desenvolvimento de formulações de alta qualidade e avaliação da toxidade dos produtos. A EMBRAPA cabia: obter as autorizações necessárias para o cumprimento da legislação de acesso ao patrimônio genético; responsabilizar-se pelas atividades previstas no Plano de Trabalho; e disponibilizar as estirpes a serem utilizadas na execução desse contrato. Dentre as atividades do IMAmt, estavam: disponibilização de recursos humanos para a execução do contrato, responsabilizando-se pelo pagamento das despesas; contratação de pesquisador; realização de compras (materiais de consumo e equipamentos) e contratação de serviços. As atividades da Comdeagro eram: obter as autorizações necessárias para regular o cumprimento da legislação de acesso ao patrimônio genético e responsabilizar-se pela gestão do processo de obtenção dos registros dos produtos que viessem a ser obtidos, junto às autoridades competentes, em especial junto à Agência Nacional.

\section{SÍNTESE INTRACASO}

Considerando as características das alianças investigadas, bem como a descrição dos parceiros envolvidos e das inovações geradas, apresenta-se a seguir uma síntese intracaso (Figura 2).

\begin{tabular}{|c|c|c|c|}
\hline \multirow[b]{2}{*}{ Características } & \multicolumn{3}{|c|}{ Descrição sintetizada } \\
\hline & $\begin{array}{c}\text { Aliança (1) Embalagens anatômicas } \\
\text { para frutas }\end{array}$ & $\begin{array}{c}\text { Aliança (2) } \\
\text { Cultivar de cevada - BRS } \\
\text { Quaranta }\end{array}$ & $\begin{array}{c}\text { Aliança (3) } \\
\text { INOVA-Bti - inseticida } \\
\text { biológico }\end{array}$ \\
\hline Tipo de inovação & Processo agroindustrial & Produto (ecoinovação) & Produto \\
\hline Tema associado & $\begin{array}{l}\text { Agroindústria, segurança alimentar, } \\
\text { nutrição e saúde. }\end{array}$ & $\begin{array}{c}\text { Agricultura familiar, } \\
\text { agroindústria, melhoramento } \\
\text { genético e produção vegetal }\end{array}$ & $\begin{array}{l}\text { Bioprodutos, formulações e } \\
\text { congêneres }\end{array}$ \\
\hline $\begin{array}{l}\text { Ano de } \\
\text { lançamento }\end{array}$ & 2011 & 2002 & 2016 \\
\hline Ano de conclusão & 2015 & 2015 & 2016 \\
\hline $\begin{array}{l}\text { Principais } \\
\text { aplicações }\end{array}$ & Transporte e armazenamento de frutas & Cultura de inverno & $\begin{array}{c}\text { Reservatórios de água para o } \\
\text { consumo, locais apropriados } \\
\text { para a proliferação ou ligado a } \\
\text { outros meios de controle do } \\
\text { mosquito. }\end{array}$ \\
\hline $\begin{array}{l}\text { Principais } \\
\text { impactos }\end{array}$ & $\begin{array}{l}\text { Diminuição de perdas e desperdícios das } \\
\text { frutas; aumento da eficiência no trabalho; } \\
\text { decomposição mais rápida na natureza. }\end{array}$ & $\begin{array}{l}\text { Aumento de produtividade; } \\
\text { dispensa parcial ou total das } \\
\text { aplicações de fungicida. }\end{array}$ & $\begin{array}{l}\text { Controle das larvas do } \\
\text { mosquito Aedes aegypti, } \\
\text { transmissor do vírus da } \\
\text { dengue, chikungunya e zika; } \\
\text { não prejudica o meio } \\
\text { ambiente. }\end{array}$ \\
\hline $\begin{array}{l}\text { Depósitos de } \\
\text { patentes }\end{array}$ & 39 & 1 & $\begin{array}{c}\text { Não se aplica (segredo } \\
\text { industrial) }\end{array}$ \\
\hline Publicações & 4 artigos e 2 capítulos & 1 fôlder & 1 fôlder \\
\hline $\begin{array}{l}\text { Atividades de } \\
\text { P\&D }\end{array}$ & $\begin{array}{l}\text { Pesquisa: levantamento dos problemas } \\
\text { encontrados pelos produtores para } \\
\text { transporte e armazenamento de frutas e } \\
\text { hortaliças; seleção da fibra mais } \\
\text { adequada para formação do compósito. } \\
\text { Desenvolvimento: agregar fibra no } \\
\text { compósito, modelagem e design das } \\
\text { embalagens. }\end{array}$ & $\begin{array}{l}\text { Desenvolvimento: } \\
\text { melhoramento genético da } \\
\text { cevada; Pesquisa: } \\
\text { experimentação para } \\
\text { avaliação do desempenho } \\
\text { agronômico das linhagens. }\end{array}$ & $\begin{array}{c}\text { Indicação de estirpes; } \\
\text { otimização do processo de } \\
\text { produção das estirpes; } \\
\text { desenvolvimento de } \\
\text { formulações de alta qualidade } \\
\text { e avaliação da toxidade dos } \\
\text { produtos. }\end{array}$ \\
\hline
\end{tabular}




\begin{tabular}{|c|c|c|c|}
\hline $\begin{array}{l}\text { Principais } \\
\text { parceiros }\end{array}$ & $\begin{array}{l}\text { IMA (não conectado ao } \\
\text { mercado) e INT (não } \\
\text { conectado ao mercado) }\end{array}$ & $\begin{array}{c}\text { AmBev (conectado ao mercado) } \\
\text { e FAPA (não conectado ao } \\
\text { mercado) }\end{array}$ & $\begin{array}{l}\text { IMAmt (não conectado) e Comdeagro } \\
\text { (conectado ao mercado) }\end{array}$ \\
\hline Início da aliança & 2010 & 2002 & 2016 \\
\hline $\begin{array}{l}\text { Duração da } \\
\text { aliança* }\end{array}$ & 5 anos (médio prazo*) & 12 anos (longo prazo*) & 1 ano (curto prazo*) \\
\hline $\begin{array}{l}\text { Instrumento de } \\
\text { formalização }\end{array}$ & Termo de convênio & $\begin{array}{l}\text { Contrato de cooperação técnica } \\
\text { e financeira }\end{array}$ & Contrato de Cooperação Técnica \\
\hline $\begin{array}{l}\text { Objetivo da } \\
\text { aliança }\end{array}$ & $\begin{array}{c}\text { Desenvolvimento de } \\
\text { embalagens valorizáveis para } \\
\text { o acondicionamento de frutas } \\
\text { e hortaliças. }\end{array}$ & $\begin{array}{l}\text { Estabelecer as condições para } \\
\text { cooperação técnica e financeira } \\
\text { entre a EMBRAPA, a AmBev e } \\
\text { a FAPA para a obtenção de } \\
\text { novas cultivares de cevada. }\end{array}$ & $\begin{array}{l}\text { Desenvolvimento de produtos à base } \\
\text { de Bacillus thuringiensis var. } \\
\text { israelenses e de Bacillus sphaericus, } \\
\text { para controle de Simulium spp, Culex } \\
\text { quinquefasciatua, Anopheles spp e } \\
\text { Aedes aegypti. }\end{array}$ \\
\hline $\begin{array}{l}\text { Composição do } \\
\text { recurso financeiro }\end{array}$ & $\begin{array}{l}\text { BNDES: R } \$ 7.500 .217,00 ; \\
\text { IMA, INT e EMBRAPA: } \\
\text { R } \$ 4.179 .000,00 \text { (aporte) }\end{array}$ & $\begin{array}{c}\mathrm{R} \$ 4.199 .195,30, \text { sendo que } \\
\mathrm{R} \$ 1.568 .972,30 \text { se refere à } \\
\text { participação da EMBRAPA; } \\
\mathrm{R} \$ 1.362 .612,00, \text { da AmBev; e } \\
\mathrm{R} \$ 1.267 .611,00 \text {, da FAPA. }\end{array}$ & $\begin{array}{c}\text { Sem repasse de recursos financeiros } \\
\text { entre as instituições. Valores } \\
\text { aportados: EMBRAPA R } \$ \\
\text { 120.000,00; IMAmt R } \$ 60.000,00 ; \\
\text { Comdeagro } \mathrm{R} \$ 60.000,00 \text {. }\end{array}$ \\
\hline $\begin{array}{l}\text { Papel da } \\
\text { EMBRAPA }\end{array}$ & $\begin{array}{l}\text { Levantamentos das } \\
\text { necessidades de cada } \\
\text { produto, características } \\
\text { apropriadas das embalagens. }\end{array}$ & $\begin{array}{l}\text { Atividades de cruzamentos; } \\
\text { avanço de gerações e seleção } \\
\text { de progênies e realização de } \\
\text { testes de avaliação e de valor } \\
\text { de cultivo e uso - VCU. }\end{array}$ & $\begin{array}{l}\text { Obter as autorizações necessárias } \\
\text { para cumprimento da legislação de } \\
\text { acesso ao patrimônio genético; } \\
\text { responsabilizar-se pelas atividades do } \\
\text { Plano de Trabalho; e disponibilizar as } \\
\text { estirpes a serem utilizadas no } \\
\text { contrato. }\end{array}$ \\
\hline $\begin{array}{l}\text { Papel do } \\
\text { parceiro } 1\end{array}$ & $\begin{array}{l}\text { Parceiro IMA: Selecionar, } \\
\text { tratar e caracterizar rejeitos } \\
\text { agrícolas que pudessem ser } \\
\text { utilizados nos compósitos } \\
\text { polímeros; selecionar os } \\
\text { materiais poliméricos mais } \\
\text { adequados à preparação dos } \\
\text { compósitos. }\end{array}$ & $\begin{array}{l}\text { Parceiro AmBev: Realização de } \\
\text { testes de avaliação de } \\
\text { qualidade de malte e cerveja e } \\
\text { validação de desempenho } \\
\text { agronômico de cultivares } \\
\text { registradas em nome da } \\
\text { EMBRAPA. }\end{array}$ & $\begin{array}{l}\text { Parceiro IMAmt: Disponibilizar } \\
\text { recursos humanos para a execução } \\
\text { do contrato, responsabilizando-se } \\
\text { pelo pagamento das despesas; } \\
\text { realizar contratação de pesquisador; } \\
\text { realizar compras (materiais de } \\
\text { consumo e equipamentos) e } \\
\text { contratações de serviços. }\end{array}$ \\
\hline $\begin{array}{l}\text { Papel do } \\
\text { parceiro } 2\end{array}$ & $\begin{array}{c}\text { Parceiro INT: } \\
\text { Desenvolvimento dos projetos } \\
\text { das embalagens primárias, } \\
\text { secundárias e terciárias no } \\
\text { campo do design. }\end{array}$ & $\begin{array}{l}\text { Parceiro FAPA: Realização de } \\
\text { testes de avaliação de } \\
\text { qualidade de malte e cerveja e } \\
\text { validação de desempenho } \\
\text { agronômico de cultivares } \\
\text { registradas em nome da } \\
\text { EMBRAPA e testes de } \\
\text { avaliação e de VCU em } \\
\text { linhagens desenvolvidas pela } \\
\text { EMBRAPA. }\end{array}$ & $\begin{array}{l}\text { Parceiro Comdeagro: Obter as } \\
\text { autorizações necessárias para regular } \\
\text { o cumprimento da legislação de } \\
\text { acesso ao patrimônio genético e } \\
\text { responsabilizar-se pela gestão do } \\
\text { processo de obtenção dos registros } \\
\text { dos produtos que viessem a ser } \\
\text { obtidos junto às autoridades } \\
\text { competentes e produzir o } \\
\text { bioinseticida. }\end{array}$ \\
\hline
\end{tabular}

Figura 2: Síntese intracaso das alianças estratégicas de P\&D investigadas.

Fonte: Elaboração própria (2017).

\section{DISCUSSÃO DOS RESULTADOS}

Este capítulo contempla a discussão sobre os resultados obtidos e o confronto teórico-empírico, gerados pelas três alianças investigadas e pelas proposições por este estudo levantadas. As entrevistas em profundidade foram realizadas em duas instituições de cada aliança, no entanto, a partir das entrevistas e da análise dos dados secundários, informações de outros parceiros de cada aliança foram evidenciadas. 


\begin{tabular}{|c|c|}
\hline $\begin{array}{l}\text { Categorias de } \\
\text { análise }\end{array}$ & Evidências (trechos das entrevistas) \\
\hline $\begin{array}{l}\text { Reincidência de } \\
\text { parceria } \\
\text { (Alianças para o } \\
\text { desenvolvimento) }\end{array}$ & $\begin{array}{l}\text { - Aliança 1: "A EMBRAPA já havia celebrado parcerias prévias com o IMA em outros projetos" (O } \\
\text { pesquisador da EMBRAPA Agroindústria de Alimentos). } \\
\text { - Aliança 1: "A EMBRAPA, o IMA e o INT já haviam trabalhado em conjunto, em projetos distintos" } \\
\text { (pesquisadora do IMA) } \\
\text { - Aliança 3: "Temos outros projetos em parceria com a EMBRAPA em andamento" (pesquisador do } \\
\text { IMAmt). } \\
\text { - Aliança 3: "O CENARGEN está realizando diversas pesquisas com o IMAmt" (chefe-geral do } \\
\text { CENARGEN). } \\
\text { - Aliança 3: "O IMAmt é um grande parceiro" (chefe de T\&T CENARGEN). }\end{array}$ \\
\hline $\begin{array}{l}\text { Vantagens } \\
\text { reincidência } \\
\text { parceria } \\
\text { (Alianças para o } \\
\text { desenvolvimento) }\end{array}$ & $\begin{array}{l}\text { - Aliança 1: "Quando se conhecem o parceiro, sua expertise, seu laboratório, sua estrutura, sua } \\
\text { condição e responsabilidade, tanto a comunicação quanto o trabalho ficam facilitados" (pesquisadora } \\
\text { do IMA) } \\
\text { - Aliança 1: "Com a repetição há a possibilidade de fazer uma previsão mais realista dos custos } \\
\text { envolvidos, pois, às vezes, os custos são subestimados, assim como os gastos para P\&D" (chefe de } \\
\text { T\&T da EMBRAPA Agroindústria de Alimentos) } \\
\text { - Aliança 3: "A repetição dos parceiros apresenta vantagem porque já se conhecem as pessoas e os } \\
\text { modos de operação de uma empresa, ganhando-se tempo. No caso do IMAmt, sabemos o que eles } \\
\text { podem fazer e o que não podem, em termos de negociação de valores" (chefe de T\&T do } \\
\text { CENARGEN). } \\
\text { - Aliança 3: "Você já conhece todo trâmite dentro (...), então como você já conhece todas as } \\
\text { pessoas, conhece os atores, você já sabe toda linguagem e o lado de desenvolver o projeto então fica } \\
\text { mais fácil" (pesquisador IMAmt). }\end{array}$ \\
\hline $\begin{array}{l}\text { Confiança (Alianças } \\
\text { para o } \\
\text { desenvolvimento) }\end{array}$ & $\begin{array}{l}\text { - Aliança 1: "Havia um clima de confiança entre todos, sem qualquer preocupação acerca de roubo } \\
\text { de informações entre os integrantes envolvidos" (pesquisadora entrevistada do IMA). } \\
\text { - Aliança 1: "Quando você já conhece a forma de trabalho do outro, então se você repete é porque } \\
\text { deu certo, então você confia naquilo que o outro faz, conforme o outro trabalha, então você acaba } \\
\text { criando esse elo de confiança que faz com que o trabalho ande de uma forma mais rápida" (Chefe de } \\
\text { T\&T da Embrapa Agroindústria de Alimentos). } \\
\text { - Aliança 3: "Se não houver confiança entre os envolvidos, a execução das atividades fica mais } \\
\text { difícil" (pesquisadora do CENARGEN). }\end{array}$ \\
\hline $\begin{array}{l}\text { Diversidade de } \\
\text { parceiros (Aliança } \\
\text { para pesquisa) }\end{array}$ & $\begin{array}{l}\text { - Aliança 2: "A Embrapa tem 95\% do mercado de cultivares de cevada do Brasil, a cerveja brasileira } \\
\text { depende da Embrapa em termos de genética, só que a Embrapa não detém todo o conteúdo para o } \\
\text { desenvolvimento de uma cultivar, por exemplo, os aspectos relacionados à malteação (malte de boa } \\
\text { qualidade) (...) isso tem que ser feito por parceiros, então o que acontece, um pedaço é da Embrapa e } \\
\text { um pedaço é do parceiro" (Chefe de T\&T da EMBRAPA Trigo). } \\
\text { - Aliança 2: "Cooperativas têm responsabilidade pelo sucesso econômico do agricultor, então a } \\
\text { Embrapa estando próxima a ela é mais fácil entender qual produto tecnológico desenvolver para o } \\
\text { sistema funcionar" (Chefe de T\&T da EMBRAPA Trigo). } \\
\text { - Aliança 2: "A AmBev atende mais RS, Agrária é região da cooperativa (estado do Paraná), então } \\
\text { nisso o clima influencia, às vezes, a mesma variedade não vai bem em um lugar e não no outro, a } \\
\text { questão da parceria é muito importante na parte operacional do programa também (...) cada um faz } \\
\text { sua parte e depois juntas os dados e analisa conjuntamente" (Pesquisador da EMBRAPA Trigo). } \\
\text { - Aliança 2: "Nas parcerias é sempre possível adquirir conhecimento, no caso da cevada cervejeira } \\
\text { é entender o processo de qualidade para um determinado fim, nesse caso a cervejaria, esse pessoal } \\
\text { está sempre na ponta do conhecimento, então eles me passam quais características eu tenho que } \\
\text { buscar na cevada para atender o cliente" (Pesquisador da EMBRAPA Trigo). } \\
\text { - Aliança 2: "Nós temos parcerias principalmente na área de melhoramento genético, com a } \\
\text { finalidade de desenvolver variedades adaptadas à nossa região em função das particularidades que } \\
\text { existem aqui é uma região muito alta, muito frio, chove bastante" (Pesquisador da FAPA). } \\
\text { - Aliança 2: "Nós temos que entregar um produto de melhor qualidade para nossas indústrias e ao } \\
\text { mesmo tempo temos que entregar uma tecnologia ou uma variedade mais produtiva no campo" } \\
\text { (Pesquisador da FAPA). }\end{array}$ \\
\hline
\end{tabular}

Figura 3: Evidências das categorias de análise por meio de trechos de entrevistas

Fonte: Elaboração própria (2017).

Assim, na Aliança 1, que teve como propósito o desenvolvimento de embalagens anatômicas para frutas, consideradas pela EMBRAPA inovação de processo, com ênfase em atividades de P\&D e uma aliança de curto prazo, a partir das entrevistas com pesquisadores e gestores da EMBRAPA Agroindústria de Alimentos e 0 
Instituto de Macromoléculas (IMA) e análise dos dados secundários, foi possível levantar evidências relacionadas ao Instituto Nacional de Tecnologia (INT).

Com a Aliança 2, cujo objetivo foi o desenvolvimento de novas cultivares de cevada, inovação de produto, com ênfase em atividade de pesquisa de longo prazo, a partir da coleta de dados primários com a EMBRAPA Trigo e a Fundação Agrária de Pesquisa e dados secundários, foi possível fazer constatações relacionadas à Companhia de Bebidas da Américas (AmBev).

E, por fim, a Aliança 3, que teve como foco o desenvolvimento de inseticida biológico, por meio principalmente de atividades de desenvolvimento de curto prazo, a partir de entrevistas com a EMBRAPA Recursos Genéticos e Biotecnologia (CENARGEN) e o Instituto Mato-Grossense do Algodão (IMAmt) foi possivel fazer inferências relacionadas a Cooperativa Mista de Desenvolvimento do Agronegócio (Comdeagro).

A partir da análise conjunta dos dados, foi possivel constatar que todas as Unidades da EMBRAPA (Agroindústria de Alimentos, Trigo e CENARGEN) investigadas e os seus parceiros (IMA, FAPA, IMAmt) possuem experiência na celebração de alianças com atores de naturezas distintas (indústria, universidades, institutos de pesquisa, cooperativas, etc.), tanto com parceiros nacionais como internacionais.

Ficou evidenciado que, nas Alianças 1 (embalagens anatômicas para frutas) e 3 (inseticida biológico), cujo foco principal das atividades foi de desenvolvimento, já haviam sido estabelecidas parcerias prévias com os mesmos parceiros (IMA, INT, IMAmt e Comdeagro), conforme relatado pelos entrevistados (Quadro 3) e também confirmado por informações no Sistema Administrativo de Informações Contratuais (SAIC) da EMBRAPA. Dentre as principais vantagens da existência da experiência prévia com parceiros pelos entrevistados da Aliança 1, foram 0 maior conhecimento do parceiro e de seus recursos, facilidade de comunicação, processos mais eficientes, obtenção de previsão mais realista dos custos envolvidos e maior agilidade às atividades. A agilidade também foi destacada pelos entrevistados da Aliança 3, uma vez que se conhecem as pessoas, o modo de operação do parceiro, além dos recursos financeiros que eles dispõem.

Esses achados corroboram com a literatura prévia que destacam que quanto maior a repetição dos parceiros na formação de parcerias, mais refinada se torna essa relação, sendo estabelecidas rotinas que facilitam a troca de informação e know-how entre os parceiros, determinando mais facilmente a tarefa que cada um deve executar (Zollo, Reuer, \& Singh, 2002; Khanna, Gulati, \& Nohria, 1998). A repetição de parceiros possibilita, ainda, elaborar contratos mais detalhados e com menores custos, pois já se tem conhecimento prévio do parceiro (Ryall \& Sampson, 2006).

Constatou-se que a confiança é um dos motivos que levam à repetição de parceiros $\mathrm{A}$ um item fundamental para que a aliança atinja seus objetivos e que as atividades sejam desenvolvidas de forma mais ágil, conforme destacado pelos entrevistados (Figura 3). Literatura prévia indicava que, mesmo havendo todas as questões formalizadas (que auxiliam na diminuição de comportamento oportunista e o roubo de informações), há 0 conhecimento da forma de trabalho do parceiro, o que indica se ele atua com responsabilidade, resultando em maior agilidade das atividades (Gulati, 1995). Além disso, a confiança faz com que haja maior motivação de haver troca mútua de informações e know-how para alcançar aprendizagem recíproca (Shakeri \& Radfar, 2017).

Assim, pode-se concluir que, quando o propósito é o desenvolvimento de curto e médio prazo, a experiência no estabelecimento de alianças estratégicas, com os mesmos parceiros, potencializa a $\mathrm{CR}$, sendo aderente à proposição 02 nas Alianças 1 (embalagens anatômicas para frutas) e 3 (inseticida biológico), uma vez que se tem maior conhecimento dos recursos (humanos, equipamento, financeiros) que as instituições possuem e podem compartilhar; adaptações nos instrumentos jurídicos (oscilando entre o maior ou menor nível de exigências); confiança relacionada à responsabilidade do parceiro; maior precisão relativa aos custos das atividades; e baixa incidência de conflito entre esses parceiros, resultando assim em maior agilidade na realização das atividades. Com relação à Aliança 02 (cultivar de cevada), a proposição 02 não se aplica, uma vez que a ênfase maior esteve relacionada às atividades de pesquisa e de longo prazo, não sendo possível analisar a aderência.

$\mathrm{Na}$ Aliança 2 (cultivar de cevada), que teve como propósito a pesquisa de longo prazo para a geração da cultivar de cevada, envolveu a participação de atores com grande diversidade de conhecimentos. Além disso, um dos parceiros é a EMBRAPA Trigo, Unidade que tem vigente, atualmente, mais de 80 instrumentos celebrados com instituições das mais distintas naturezas (fundações, cooperativas, universidades, produtores rurais, organizações estaduais de pesquisa, institutos, etc.), demonstrando uma vasta experiência em alianças com distintos parceiros.

Foi possível constatar ainda que os outros parceiros e suas conexões mercadológicas (Matriz da AmBev e suas unidades produtivas nacionais e subsidiárias internacionais, bem como a FAPA e seus demandantes de P\&D, incluindo cooperativas e agricultores), cada um com sua expertise técnica e de mercado integrada à expertise em 
P\&D da EMBRAPA Trigo, possibilitaram a compreensão das demandas da indústria, do mercado, do produtor e da região (características de solo e clima), resultando em inovação com resultados econômicos e ganhos de produtividade para o agronegócio brasileiro e a indústria cervejeira.

Conforme destaca o chefe de T\&T da EMBRAPA Trigo, há um grande aprendizado nessa parceria, uma vez que é possível ter melhor compreensão do processo da qualidade da cerveja que o mercado está buscando. As instituições conectadas ao mercado (AmBev) estão sempre na ponta do conhecimento, e elas possuem pessoas especializadas, que sabem sobre a demanda do cliente e por outro lado as cooperativas se preocupam com 0 desenvolvimento de cultivar de qualidade, pois é responsável pelo sucesso do produtor. Toda vez que se faz 0 planejamento para o desenvolvimento de uma nova variedade, o pesquisador da EMBRAPA Trigo destaca que ele se baseia nessas informações e sabe quais características necessita incorporar na cultivar, por isso a importância de apresentar uma cultivar que tenha algo inovador. 0 pesquisador ainda considera que muito do conhecimento técnico que ele possui provém dessas alianças, as quais ainda possibilitam ter acesso a informações, muitas vezes, de cunho confidencial, contribuindo para o desenvolvimento de cultivares que atendam com mais sucesso a demanda.

$O$ chefe de T\&T da Embrapa Trigo destaca que a EMBRAPA não possui todo o conhecimento para 0 desenvolvimento de uma cultivar. No caso da cevada, ela não entende os aspectos relacionados à malteação (por meio da maltaria da AmBev) e também o que os produtores de cevada necessitam no campo. Assim, os parceiros informam sobre as características necessárias, por isso a participação da AmBev e da FAPA é essencial para melhor compreensão, inclusive das demandas das regiões do Rio Grande do Sul e Paraná.

O pesquisador da FAPA (Figura 3) destaca que a formação de alianças e diversidade de conhecimento é essencial para que se consiga desenvolver cultivares adaptáveis à região do Paraná. Além disso, foi possível constatar que a FAPA está sempre em busca de um produto de qualidade que atenda tanto a indústria quanto os produtores, conforme destaca o pesquisador da FAPA.

Assim, é possível verificar que a proposição 1, que trata que quando o propósito é a pesquisa de longo prazo, a experiência no estabelecimento de alianças estratégicas, com diferentes parceiros, potencializa a $C R$, foi aderente à Aliança 02 , uma vez que, dentre as principais atividades realizadas, foram de pesquisa e a duração de longo prazo (12 anos). Por outro lado, não é possível analisar a aderência da proposição 1 às Alianças 1 (embalagens anatômicas para frutas) e 3 (inseticida biológico), visto que a ênfase maior das alianças estava relacionada às atividades de desenvolvimento e ao período de curto e médio prazo.

A Figura 4 apresenta a análise da aderência às proposições relacionadas à experiência no estabelecimento de alianças estratégicas de P\&D, destacando, de forma sintética, a potencialização da CR em alianças com reincidência de parceiros, para alianças de desenvolvimento; e em alianças de pesquisa de longo prazo, quando estabelecidas com diferentes parceiros.

A partir do um confronto teórico-empírico foi possível inferir que a reincidência de parceiros pode potencializar a $\mathrm{CR}$, quando a natureza da atividade for de desenvolvimento, uma vez que possibilita maior conhecimento dos recursos do parceiro, precisão de custos das atividades, baixa incidência de conflitos e maior agilidade no alcance dos resultados. Além disso, a confiança é um dos motivos que levam à repetição (Shakeri \& Radfar, 2017). Já a experiência com diversos parceiros, detentores de distintos conhecimentos científicos e mercadológicos, pode potencializar o alcance dos resultados de pesquisa, contribuindo para a geração de inovação (o cultivar de cevada 'Quaranta' é um exemplo disso) (Figura 4 e Figura 5). 


\begin{tabular}{|c|c|c|c|}
\hline \multirow[b]{2}{*}{$\begin{array}{c}\text { Proposições } \\
\text { atreladas à } \\
\text { experiência no } \\
\text { estabelecimento de } \\
\text { alianças estratégicas } \\
\text { de P\&D }\end{array}$} & \multicolumn{3}{|c|}{ Aderência frente às proposições levantadas } \\
\hline & $\begin{array}{l}\text { Embalagens anatômicas } \\
\text { para frutas: uma } \\
\text { inovação de processo }\end{array}$ & $\begin{array}{c}\text { Cultivar de cevada - BRS } \\
\text { Quaranta: uma inovação de } \\
\text { produto }\end{array}$ & $\begin{array}{l}\text { INOVA-Bti - inseticida } \\
\text { biológico: uma inovação de } \\
\text { produto }\end{array}$ \\
\hline $\begin{array}{c}\text { (P1) Quando o } \\
\text { propósito é a pesquisa } \\
\text { de longo prazo, a } \\
\text { experiência no } \\
\text { estabelecimento de } \\
\text { alianças estratégicas, } \\
\text { com diferentes } \\
\text { parceiros, potencializa } \\
\text { a CR. }\end{array}$ & $\begin{array}{l}\text { NÃO SE APLICA } \\
\text { Propósito da aliança foi o } \\
\text { desenvolvimento de } \\
\text { médio prazo. }\end{array}$ & $\begin{array}{c}\text { ADERENTE } \\
\text { A aliança envolveu a participação } \\
\text { de grande diversidade de } \\
\text { parceiros (empresa de pesquisa } \\
\text { pública, fundação de pesquisa, } \\
\text { indústria, cooperativa e } \\
\text { produtores), cujo conhecimento } \\
\text { distinto possibilitou a } \\
\text { compreensão das demandas da } \\
\text { indústria, mercado e produtor; } \\
\text { ampliação da área de abrangência } \\
\text { para a realização da pesquisa. }\end{array}$ & $\begin{array}{c}\text { NÃO SE APLICA } \\
\text { Propósito da aliança foi o } \\
\text { desenvolvimento de curto } \\
\text { prazo. }\end{array}$ \\
\hline $\begin{array}{c}\text { (P2) Quando o } \\
\text { propósito é o } \\
\text { desenvolvimento de } \\
\text { curto prazo e médio } \\
\text { prazo, a experiência } \\
\text { no estabelecimento de } \\
\text { alianças estratégicas, } \\
\text { com os mesmos } \\
\text { parceiros, potencializa } \\
\text { a CR. }\end{array}$ & $\begin{array}{c}\text { ADERENTE } \\
\text { Já haviam sido } \\
\text { estabelecidas alianças } \\
\text { prévias com os parceiros } \\
\text { envolvidos para outros } \\
\text { projetos. A repetição } \\
\text { proporciona maior } \\
\text { conhecimento e confiança } \\
\text { dos parceiros e dos } \\
\text { recursos do parceiro; } \\
\text { facilidade de } \\
\text { comunicação, resultando } \\
\text { em maior agilidade nas } \\
\text { atividades. }\end{array}$ & $\begin{array}{l}\text { NÃO SE APLICA } \\
\text { Propósito da aliança para } \\
\text { pesquisa de longo prazo. }\end{array}$ & $\begin{array}{c}\text { ADERENTE } \\
\text { Já haviam sido estabelecidas } \\
\text { parcerias prévias com o } \\
\text { parceiro; atualmente, estão } \\
\text { vigentes } 21 \text { alianças entre a } \\
\text { EMBRAPA e o IMAmt; três } \\
\text { pesquisadores do IMAmt } \\
\text { atuam dentro do CENARGEN. } \\
\text { A repetição contribuiu para dar } \\
\text { maior agilidade às atividades, } \\
\text { pois se conhecem as pessoas, } \\
\text { os recursos, conhecimentos, } \\
\text { as limitações, as questões de } \\
\text { valores e os trâmites internos } \\
\text { na instituição. }\end{array}$ \\
\hline
\end{tabular}

Figura 4. Análise das proposições atreladas à experiência no estabelecimento de alianças estratégicas de P\&D.

Fonte: Elaboração própria (2017).

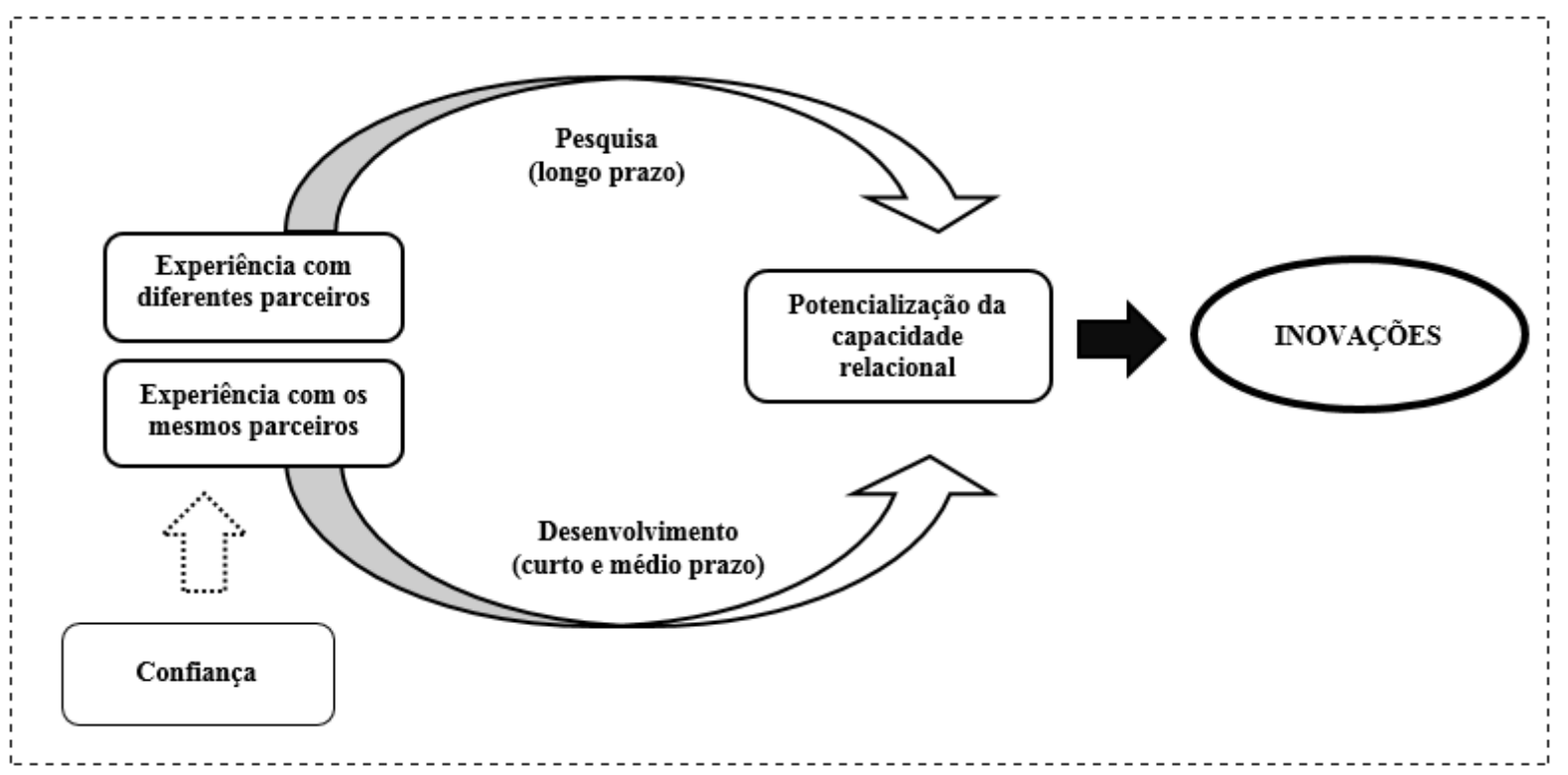

Figura 5. Framework propositivo

Fonte: Elaboração própria (2017). 


\section{CONCLUSÕES}

0 presente estudo apresenta contribuições para 0 avanço do conhecimento em gestão estratégica de alianças de P\&D, especificamente na linha de estratégia de inovação. A primeira delas refere-se à experiência, visto que estudos prévios já haviam apresentado a importância da experiência acumulada e da repetição de parceiros para o desenvolvimento da CR e 0 aumento das chances de sucessos de alianças posteriores (Anand \& Khanna, 2000; Schilke \& Goerzen, 2010). Neste estudo, entretanto, foi possível constatar que a repetição de parceiros potencializa, de fato, a CR em alianças cuja ênfase é o desenvolvimento. No caso das alianças de P\&D, cuja ênfase é a pesquisa, é a experiência com maior diversidade de parceiros de diferentes naturezas (cooperativa, indústria, instituto de pesquisa, agricultor) que potencializa a $\mathrm{CR}$.

Este estudo apresenta contribuição aos gestores de instituições de P\&D, alertando para a importância de estarem atentos nas escolhas dos parceiros em alianças estratégicas de P\&D. Caso a ênfase da aliança seja desenvolvimento, deve-se priorizar a repetição de parceiros desde que haja a confiança. Já se a ênfase da aliança é a pesquisa, a diversificação de parceiros pode potencializar a CR e levar aos resultados, no caso, geração de inovações.

Por se tratar de uma pesquisa qualitativa, este estudo apresenta como limitante a seleção restrita do número de casos, não sendo assim possível a sua generalização para outras alianças de P\&D, para desenvolvimento de inovação, nem seus resultados generalizados em relação às outras Unidades da EMBRAPA e de seus parceiros. Cabe também esclarecer que as proposições que fundamentaram o estudo decorreram da revisão da literatura e da expectativa do pesquisador quanto ao fenômeno estudado, sendo a interpretação restrita aos casos selecionados intencionalmente, o que impossibilita a realização de generalizações.

Assim, estudos futuros poderiam analisar a influência da CR individual sobre a CR da instituição em alianças estratégicas para a realização de P\&D com fins de gerar inovações. Como futuras pesquisas, ainda, sugere-se a ampliação da análise, a partir de um número maior de instituições que celebram alianças estratégicas para a realização de P\&D e de inovações agropecuárias.

\section{REFERÊNCIAS}

AGRÁRIA. (2019a). Fundação de Pesquisa. Recuperada em 18 jan., 2019 de $<$ http://www.agraria.com.br/agraria_pesquisa.php>.

AGRÁRIA. (2019b). Cooperativa Agrária. Recuperada em 18 jan., 2019 de $<$ <ttp://www.agraria.com.br/agraria.php>.

Ahuja, G. (2000). Collaboration networks, structural holes, and innovation: A longitudinal study. Administrative science quarterly, 45(3), 425-455.

Alves, F. S. (2015). Capacidades relacionais em cooperações para desenvolvimento de tecnologias com e sem fins lucrativos. 373 f. Tese de Doutorado em Administração, Universidade Federal do Paraná, Curitiba.

AMBEV. (2019). Sobre a AmBev. Recuperada em 18 jan., 2019 de <http://www.ambev.com.br/sobre/>.

Anand, B. N., \& Khanna, T. (2000). Do firms learn to create value? The case of alliances. Strategic management journal, 45(3), 295-315.

Anderson, A. R., Benavides-Espinosa, M. Del M., \& Mohedano-Suanes, A. (2011). Innovation in services through learning in a joint venture. The Service Industries Journal, 31(12), 2019-2032.

Arino, A., \& De La Torre, J. (1998). Learning from failure: Towards an evolutionary model of collaborative ventures. Organization science, 9(3), 306-325.

Barbieri, J. C. et al. (2010). Inovação e Sustentabilidade: Novos Modelos E Proposições/Innovation And Sustainability: New Models And Propositions/Innovación Y Sostenibilidad: Nuevos Modelos Y Proposiciones. Revista de Administração de Empresas, 50(2), 146.

Barney, J. (1991). Firm resources and sustained competitive advantage. Journal of management, 17(1), 99-120.

Bishop, K., D'este, P. \& Neely, A. (2011). Gaining from interactions with universities: Multiple methods for nurturing absorptive capacity. Research Policy, 40(1), 30-40. 
Briones, N. (2016). Gigante da inovação, Embrapa faz milagre com 1,5\% do PIB destinado à ciência e tecnologia. Recuperada em 28 dez., 2019 de <https://brasilamericaeconomia.com.br/artigos/gigante-da-inovacao-embrapa-fazmilagre-com-15-do-pib-destinado-ciencia-e-tecnologia>.

Brockhoff, K., \& Teichert, T. (1995). Cooperative R\&D and partners' measures of success. International Journal of Technology Management, 10(1), 111-123.

Carayannis, E. G., Barth, T. D., \& Campbell, D. F. J. (2012). The Quintuple Helix innovation model: global warming as a challenge and driver for innovation. Journal of Innovation and Entrepreneurship, 1(1), 2.

CEPEA. Centro de Estudos Avançados em Economia Aplicada. Recuperada em 18 out., 2016 de $<$ http://cepea.esalq.usp.br/pib/>.

Chesbrough, H. (2006). Open innovation: a new paradigm for understanding industrial innovation. In Chesbrough, H., Wanhaverbeke, W. \& West, J. (Eds.), Open innovation: Researching a new paradigm (1-12). New York, Oxford.

Contini, E. et al. (2012). Exportações Motor do agronegócio brasileiro. Revista de Política Agrícola, 21(2), 88102.

Costa, P. R., Porto, G. S., \& Silva, A. T. B. (2012). Capacidades dinâmicas de inovação e cooperação: aspectos da trajetória e da maturidade das multinacionais brasileiras. In XV SemeAD. 15. São Paulo.

Cella-De-Oliveira, F. A. \& Munck, L. (2014). Uma proposta de mensuração da ecoeficiência a partir das competências organizacionais e do agir social. Revista de Gestão Social e Ambiental, 8(1), 73-88.

Chais, C. (2015). Transferência de tecnologia entre universidades e empresas: os casos UNICAMP-SP e UNISINOS-RS. 107 f. Dissertação de Mestrado em Administração, Universidade de Caxias do Sul, Caxias do Sul.

Creswell, J. (2017). Research design: Qualitative, quantitative, and mixed methods approaches. SAGE publications: London.

Cui, A. S., \& O'connor, G. (2012). Alliance portfolio resource diversity and firm innovation. Journal of Marketing, 76(4), 24-43.

Cyert, R. M. \& Goodman, P. S. (1997). Creating effective university-industry alliances: An organizational learning perspective. Organizational dynamics, 25(4), 45-58.

Das, T. K. \& Teng, B.-S. A resource-based theory of strategic alliances. Journal of management, 26(1), 31-61.

De Carli, C. R. \& Wehrmann, M. E. S. de F. (2007). EMBRAPA: Precursora da parceria público-privada no Brasil. Cadernos de Estudos e Pesquisas. Recuperado em 18 jan., 2019 de $<$ <ttp://www.revista.universo.edu.br/index.php?journal=1studospesquisa2\&page=article\&op=viewArticle\&path $\% 5$ $B \% 5 D=110 />$.

Delmas, M. \& Toffel, M. W. (2004). Stakeholders and environmental management practices: an institutional framework. Business strategy and the Environment, 13(4), 209-222.

Dimaggio, P. J. \& Powell, W. W. (2000). The iron cage revisited institutional isomorphism and collective rationality in organizational fields. Economics meets sociology in strategic management. Emerald Group Publishing Limited, 143-166.

Donada, C., Nogatchewsky, G. \& Pezet, A. (2016). Understanding the relational dynamic capability-building process. Strategic Organization, 14(2), 93-117.

Dossa, A. A. \& Segatto, A. P. (2010). Pesquisas cooperativas entre universidades e institutos públicos no setor agropecuário brasileiro: um estudo na Embrapa. Revista de Administração Pública, 44(6), 1327-1352.

Draulans, J. et al. (2003). Building alliance capability: Management techniques for superior alliance performance. Long range planning, 36(2), 151-166.

Du, J., Leten, B. \& Vanhaverbeke, W. (2014). Managing open innovation projects with science-based and marketbased partners. Research Policy, 43(5), 828-840.

Dyer, J. H. \& Singh, H. (1998). The relational view: Cooperative strategy and sources of interorganizational competitive advantage. Academy of management review, 23(4), 660-679. 
EMBRAPA. (2016a). Embrapa em números. Recuperado em 26 dez., 2018 de https://www.embrapa.br/embrapaem-numeros>.

EMBRAPA. (2017a). Apresentação. Recuperado em 20 abr., 2017 de https://www.embrapa.br/agroindustria-dealimentos/apresentacao>.

EMBRAPA. (2017b). Desenvolvimento de embalagens anatômicas para frutas. Recuperado em 20 abr., 2017 de $<$ https://www.embrapa.br/busca-de-produtos-processos-e-servicos/-/produto-servico/1201/desenvolvimento-deembalagem-anatomicas-para-aumentar-a-vida-util-de-manga-caqui-e-mamao-papaya> .

EMBRAPA. (2017c). Pesquisa desenvolve embalagens anatômicas para frutas. Recuperado em 17 abr., 2017 de $<$ https://www.embrapa.br/busca-de-noticias/-/noticia/10847708/pesquisa-desenvolve-embalagens-anatomicas-parafrutas>.

EMBRAPA. (2017d). Apresentação. Recuperado em 05 mai., 2017 de $<$ https://www.embrapa.br/trigo/apresentacao>.

MBRAPA. (2017e). Cevada -BRS Quaranta. Recuperado em 25 abr., 2017 de <https://www.embrapa.br/busca-deprodutos-processos-e-servicos/-/produto-servico/3049/cevada---brs-quaranta>.

EMBRAPA. (2017f). BRS Quaranta. Recuperado em 14 mai., 2017 de <https://ainfo.cnptia.embrapa.br/digital/bitstream/item/140618/1/ID43598-FD390BRSQuaranta.pdf>.

EMBRAPA. (2017g). INOVA-Bti - inseticida biológico. Recuperado em 14 mai., 2017 de $<$ https://www.embrapa.br/busca-de-produtos-processos-e-servicos/-/produto-servico/3435/inova-bti--inseticidabiologico>.

EMBRAPA. (2017h). Apresentação. Recuperado em 14 mai., 2017 de <https://www.embrapa.br/recursosgeneticos-e-biotecnologia/apresentacao>.

Etzion, D. (2007). Research on organizations and the natural environment, 1992-present: A review. Journal of Management, 33(4), 637-664.

Fabrizio, K. R. (2009). Absorptive capacity and the search for innovation. Research policy, 38(2), 255-267.

Feller, J. et al. (2013). How companies learn to collaborate: emergence of improved inter-organizational processes in R\&D alliances. Organization Studies, 34(3), 313-343.

George, G., Zahra, S. A., \& Wood Jr, D. R. (2002). The effects of business-university alliances on innovative output and financial performance: a study of publicly traded biotechnology companies. Journal of business Venturing, 17(6), 577-609.

Gil, A. C. (2008). Métodos e técnicas de pesquisa social (6a ed.). São Paulo: Atlas.

Creswell, J. (2017). Research design: Qualitative, quantitative, and mixed methods approaches. SAGE publications: London.

Godoy, A. S. (1995). Pesquisa qualitativa: tipos fundamentais. Revista de Administração de empresas, 35(3), 20 29.

Grant, R. M. (1991). The resource-based theory of competitive advantage: implications for strategy formulation. California management review, 33(3), 114-135.

Gulati, R. (1995). Does familiarity breed trust? The implications of repeated ties for contractual choice in alliances. Academy of management journal, 38(1), 85-112.

Gulati, R. (1998). Alliances and networks. Strategic management journal, 19(4), 293-317.

Hamel, G. (1991). Competition for competence and interpartner learning within international strategic alliances. Strategic management journal, 12(S1), 83-103.

Hagedoorn, J. (2003). Sharing intellectual property rights-an exploratory study of joint patenting amongst companies. Industrial and Corporate Change, 12(5), 1035-1050.

Heimeriks, K. H., Duysters, G., \& Vanhaverbeke, W. (2007). Learning mechanisms and differential performance in alliance portfolios. Strategic organization, 5(4), 373-408. 
Heimeriks, K. H., Klijn, E., \& Reuer, J. J. (2009). Building capabilities for alliance portfolios. Long Range Planning, 42(1), 96-114.

Helfat, C. E. et al. (2009). Dynamic capabilities: Understanding strategic change in organizations (p. 146). New Jersey: Blackwell Publishing.

Herriott, S. R., Levinthal, D., \& March, J. G. (1985). Learning from experience in organizations. The American Economic Review, 75(2), 298-302.

Hitt, M. A., Ireland, R. D., \& Lee, H. (2000). Technological learning, knowledge management, firm growth and performance: an introductory essay. Journal of Engineering and Technology management, 17(3-4), 231-246.

Hoffmann, W. H. (2005). How to manage a portfolio of alliances. Long range planning, 38(2), 121-143.

IFPRI - International Food Policy Research Institute. (2012). Impact assessment. Recuperado em 27 dez., 2016 de $<$ http://www.ifpri.org/impact-assessment>.

IMA. (2019). A Instituição. Recuperado em 18 jan., 2019 de <http://www.ima.ufrj.br/instituicao/>.

INT. (2019). Sobre o INT. Recuperado em 18 jan., 2019 de <http://www.int.gov.br/sobre-o-int>.

IMAMT. (2019). O IMAmt. Recuperado em 18 jan., 2019 de <http://www.imamt.com.br/home/paginas/1/>.

Ireland, R. D., Hitt, M. A., \& Vaidyanath, D. (2002). Alliance management as a source of competitive advantage. Journal of management, 28(3), 413-446.

Ireland, R. D., \& Webb, J. W. (2007). Strategic entrepreneurship: Creating competitive advantage through streams of innovation. Business horizons, 50(1), 49-59.

Johnsen, R. E., \& Ford, D. (2006). Interaction capability development of smaller suppliers in relationships with larger customers. Industrial Marketing Management, 35(8), 1002-1015.

Kale, P., Dyer, J. H., \& Singh, H. (2002). Alliance capability, stock market response, and long-term alliance success: the role of the alliance function. Strategic management journal, 23(8), 747-767.

Kale, P., Singh, H., Perlmutter, H. (2000). Learning and protection of proprietary assets in strategic alliances: Building relational capital. Strategic management journal, 217-237.

Kale, P., \& Singh, H. (2007). Building firm capabilities through learning: the role of the alliance learning process in alliance capability and firm-level alliance success. Strategic management journal, 28(10), 981-1000.

Khanna, T., Gulati, R., \& Nohria, N. (1998). The dynamics of learning alliances: Competition, cooperation, and relative scope. Strategic management journal, 19(3), 193-210.

Koza, M., \& Lewin, A. (2000). Managing partnerships and strategic alliances: raising the odds of success. European Management Journal, 18(2), 146-151.

Kumar, R., \& Nti, K. O. (1998). Differential learning and interaction in alliance dynamics: A process and outcome discrepancy model. Organization science, 9(3), 356-367.

Lambe, C. J.; Spekman, R. E.; Hunt, S. D. (2002). Alliance competence, resources, and alliance success: conceptualization, measurement, and initial test. Journal of the academy of Marketing Science, 30(2), 141-158.

Levitt, B., \& March, J. G. (1988). Organizational learning. Annual review of sociology, 14(1), 319-338, 1988.

Lin, Feng-Jyh et al. (2016). The determinants of government-sponsored R\&D alliances. Journal of Business Research, 69(11), 5192-5195.

Luciano, M. C. (2013). Sistema nacional de inovação agrícola: um exame da interação entre Embrapa e as empresas privadas. 160 f. Dissertação de Mestrado em Economia, Universidade Estadual Paulista, Araraquara.

Marconi, M. de A. et al. (2006). Técnicas de pesquisa (6a ed.). São Paulo: Atlas.

Mcgrath, H. (2008). Developing a relational capability construct for SME network marketing using cases and evidence from Irish and Finnish SMEs. $385 \mathrm{f}$. Tese de Doutorado em Administração, Waterford Institute of Technology, Ireland.

Meyer, J. W., \& Rowan, B. (1977). Institutionalized organizations: Formal structure as myth and ceremony. American journal of sociology, 83(2), 340-363. 
Minella, E. (2013). Melhoramento da cevada. In Borém, A. (ed.). Melhoramento de espécies cultivadas (253272). Viçosa: UFV.

Mohr, J., \& Spekman, R. (1994). Characteristics of partnership success: partnership attributes, communication behavior, and conflict resolution techniques. Strategic management journal, 15(2), 135-152.

Narula, R., \& Hagedoorn, J. (1999). Innovating through strategic alliances: moving towards international partnerships and contractual agreements. Technovation, 19(5), 283-294.

Ngugi, I. K., Johnsen, R. E., \& Erdélyi, P. (2010). Relational capabilities for value co-creation and innovation in SMEs. Journal of small business and enterprise development, 17(2), 260-278.

Niesten, E., \& Jolink, A. (2015). The impact of alliance management capabilities on alliance attributes and performance: a literature review. International Journal of Management Reviews, 17(1), 69-100.

OECD. (2005). Oslo Manual: Guidelines for Collecting and Interpreting Innovation Data: The Measurement of Scientific and Technological Activities (3a ed.). Paris: OECD Publishing.

OCDE. (2013). Manual de Frascati: Metodologia proposta para a definição de pesquisa e desenvolvimento experimental. São Paulo: F Iniciativas.

Oliver, C. (1991). Strategic responses to institutional processes. Academy of management review, 16(1), 145179.

Ortiz-De-Urbina-Criado, M., Montoro-Sánchez, Á., \& Mora-Valentín, E.-M. (2014). Impact of growth strategy on mode of governance in alliances. International Business Review, 23(4), 838-848.

Parise, S., \& Casher, A. (2003). Alliance portfolios: Designing and managing your network of business-partner relationships. The Academy of Management Executive, 17(4), 25-39.

Philbin, S. P. et al. (2014). Exploring research institutes: Structures, functioning and typology. In Management of Engineering \& Technology (PICMET), Japan.

Phillips, N., Lawrence, T. B., \& Hardy, C. (2000). Inter-organizational collaboration and the dynamics of institutional fields. Journal of management studies, 37(1), 23-43.

Perkmann, M., \& Walsh, K. (2007). University-industry relationships and open innovation: Towards a research agenda. International Journal of Management Reviews, 9(4), 259-280.

Ryall, M. D., \& Sampson, R. C. (2006). Do prior alliances influence alliance contract structure? In Strategic alliances: governance and contracts (206-216). London: Palgrave Macmillan.

Sarkar, M. B., Aulakh, P. S., \& Madhok, A. (2009). Process capabilities and value generation in alliance portfolios. Organization Science, 20(3), 583-600.

Schilke, O., \& Goerzen, A. (2010). Alliance management capability: an investigation of the construct and its measurement. Journal of Management, 36(5), 1192-1219.

Schreiner, M., Kale, P., \& Corsten, D. (2009). What really is alliance management capability and how does it impact alliance outcomes and success?. Strategic Management Journal, 30(13), 1395-1419.

Shakeri, R., \& Radfar, R. (2017). Antecedents of strategic alliances performance in biopharmaceutical industry: A comprehensive model. Technological Forecasting and Social Change, 122, 289-302.

Wang, L., \& Zajac, E. J. (2007). Alliance or acquisition? A dyadic perspective on interfirm resource combinations. Strategic management journal, 28(13), 1291-1317.

Walsh, J. P., Lee, Y.-N., \& Nagaoka, S. (2016). Openness and innovation in the US: Collaboration form, idea generation and implementation. Research Policy, 45(8), 1660-1671.

Van Der Have, R. P.; Rubalcaba, L. (2016). Social innovation research: An emerging area of innovation studies?. Research Policy, 45(9), 1923-1935.

Vieira Filho, J. E. R., \& Silveira, J. M. F. Da. (2011). Modelo evolucionário de aprendizado agrícola. Revista Brasileira de Inovação, 10(2), 265-300.

Yan, Y., Zhang, S. H., \& Zeng, F. (2010). The exploitation of an international firm's relational capabilities: an empirical study. Journal of Strategic Marketing, 18(6), 473-487. 
Zaheer, A., Mcevily, B., \& Perrone, V. (1998). Does trust matter? Exploring the effects of interorganizational and interpersonal trust on performance. Organization science, 9(2), 141-159.

Zahra, S. A., \& George, G. (2002). Absorptive capacity: A review, reconceptualization, and extension. Academy of management review, 27(2), 185-203.

Zamberlan, L. et al. (2014). Pesquisa em ciências sociais aplicadas. ljuí: Unijuí.

Zollo, M., Reuer, J. J., \& Singh, H. (2002). Interorganizational routines and performance in strategic alliances. Organization science, 13(6), 701-713. 